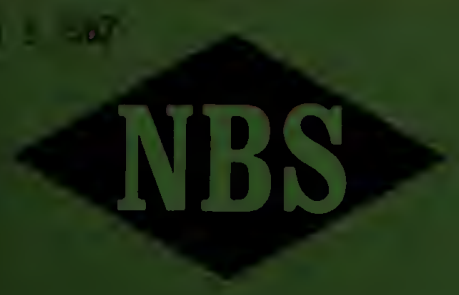

\title{
TECHNICAL
}

NOTE

278

\section{Scanning Electron Probe Microanalysis}

KURT F. J. HEINRICH

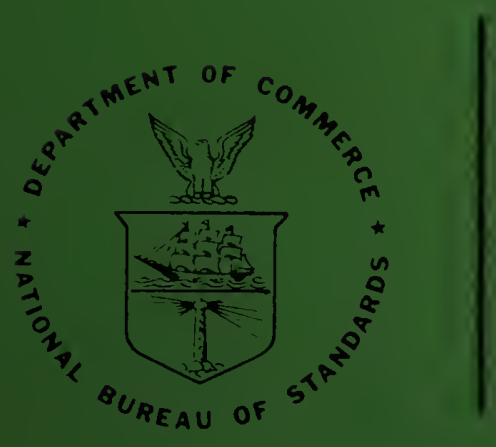

U.S. DEPARTMENT OF COMMERCE National Bureau of Standards 


\section{THE NATIONAL BUREAU OF STANDARDS}

The National Bureau of Standards ${ }^{2}$ provides measurement and technical information services essential to the efficiency and effectiveness of the work of the Nation's scientists and engineers. The Bureau serves also as a focal point in the Federal Government for assuring maximum application of the physical and engineering sciences to the advancement of technology in industry and commerce. To accomplish this mission, the Bureau is organized into three institutes covering broad program areas of research and services:

THE INSTITUTE FOR BASIC STANDARDS . . . provides the central basis within the United States for a complete and consistent system of physical measurements, coordinates that system with the measurement systems of other nations, and furnishes essential services leading to accurate and uniform physical measurements throughout the Nation's scientific community, industry, and commerce. This Institute comprises a series of divisions, each serving a classical subject matter area:

-Applied Mathematics-Electricity-Metrology-Mechanics-Heat-Atomic Physics-Physical Chemistry-Radiation Physics-Laboratory Astrophysics ${ }^{2}$-Radio Standards Laboratory, ${ }^{2}$ which includes Radio Standards Physics and Radio Standards Engineering-Office of Standard Reference Data.

THE INSTITUTE FOR MATERIALS RESEARCH . . . conducts materials research and provides associated materials services including mainly reference materials and data on the properties of materials. Beyond its direct interest to the Nation's scientists and engineers, this Institute yields services which are essential to the advancement of technology in industry and commerce. This Institute is organized primarily by technical fields:

-Analytical Chemistry-Metallurgy-Reactor Radiations-Polymers-Inorganic Materials-Cryogenics ${ }^{2}$-Materials Evaluation Laboratory-Office of Standard Reference Materials.

THE INSTITUTE FOR APPLIED TECHNOLOGY ... provides technical services to promote the use of available technology and to facilitate technological innovation in industry and government. The principal elements of this Institute are:

-Building Research-Electronic Instrumentation-Textile and Apparel Technology CenterTechnical Analysis-Center for Computer Sciences and Technology-Office of Weights and Measures-Office of Engineering Standards Services-Office of Invention and Innovation-Clearing. house for Federal Scientific and Technical Information. ${ }^{3}$

${ }^{1}$ Headquarters and Laboratories at Gaithersburg, Maryland, unless otherwise noted; mailing address Washington, D. C., 20234.

2 Located at Boulder, Colorado, 80302.

3 Located at 5285 Port Royal Road, Springfield, Virginia, 22151. 


\title{
NBSS TECHNICAL NOTE 278 \\ ISSUED FEBRUARY 3, 1967
}

\section{Scanning Electron Probe Microanalysis}

\author{
Kurt F. J. Heinrich
}

\author{
Spectrochemical Analysis Section \\ Analytical Chemistry Division \\ Institute for Materials Research
}

\begin{abstract}
NBS Technical Notes are designed to supplement the Bureau's regular publications program. They provide a means for making available scientific data that are of transient or limited interest. Technical Notes may be listed or referred to in the open literature.
\end{abstract}

For sale by the Superintendent of Documents, U.S. Government Printing Office, Washington, D.C., 20402 Price 30 cents. 


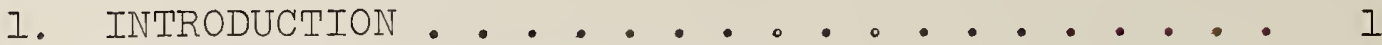

2. SCANNING ELECTRON MICROSCOPY . • . • • • . . 5

3. SCANNING X-RAY IMAGES . . . . . . . . . 14

4. THE PUISE RECORDING X-RAY IMAGE . . . . . . 14

5. THE EXPANDED CONTRAST X-RAY IMAGE . • • • . . 22

6. CONCENTRATION MAPPING . . . . . . . . . . 22

7. QUANTITATIVE AREA SCANNING . • • • • . • . 27

8. CATHODOLUMINESCENCE . • . . • • . • • . 33

9. MULTIPLE SCAN EXPOSURES . • . • • • • • . 35

10. REFERENCES •. . . . . . . . . . . . 36

LIST OF FIGURES

FIGURE NO.

1. Scanning images of gold ore specimen . . . . 4

2. Topographic effects on target current image and backscatter image . . . . . . 7

3. Secondary electron images . . . . . . . . 9

4. Micro images of recrystallized dental alloy . . II

5. Secondary electron images of a transistor under various biasing conditions . . . . . 13

6. Combined recording of secondary and backscattered electrons from a thin film magnetic memory plane, with "deflection modulation display", and secondary electron recording of the edge of a magnetic track.

7. Schematic diagrams of pulse recordings, expanded contrast scanning, and concentration mapping . . . . . . . . . . 16

8. Effect of number of accumulated $x$-ray photons. Tazewell meteorite

9. Effect of electron beam energy. Tazewell meteorite . . . . . . . . . . . 


\section{LIST OF FIGURES (con't)}

FIGURE NO.

PAGE

10. Recrystallized dental alloy, unprepared surface............... . 21

11. Tazewell meteorite: representations of the $\mathrm{Fe} \mathrm{Ka}$ signal . . . . . . . . . . . 23

12. Oscilloscope beam brightness as a function of $x$-ray signal intensity: pulse registration, expanded contrast technique, fourlevel concentration map . . . . . . . . 25

13. Dental alloy, polished surface . . . . . . 28

14. Diffusion in a specimen consisting of niobium wires imbedded in tin... . . . . . . 31

15. Sapphire crystals imbedded in a nickel base alloy ............. 34

16. Infrared cathodoluminescence scanning image. . 35 
Kurt F. J. Heinrich

\section{ABSTRACT}

The combination of electron microprobe $x$-ray emission spectrometry with the scanning techniques first developed for the scanning electron microscope permits using the scanning electron probe as a microscope sensitive to elemental composition. This technique is particularly useful in the many applications in which spatial distribution of one or more elements in a specimen is more important than local composition. Although oscilloscope representation of probe scanning is usually obtained by the simple technique of producing a dot of light for each arriving photon, more sophisticated scanning techniques such as expanded contrast registration and concentration mapping can provide more quantitative information. Signals other than $x$-rays, such as target current, electron backscatter, or cathodoluminescence may be used for image formation. Electron beam scanning can also be performed in a discontinuous fashion, so that the electron beam irradiates in succession a number of spots arranged in a square or rectangular pattern, and the number of photons registered in each position is retained in the memory of a multichannel analyzer. The application of these diverse scanning techniques is illustrated.

Key Words: Electron probe, microanalysis, x-ray spectrometry, scanning electron microscopy, electron backscatter, cathodoluminescence. 
SCANNING ELECTRON PROBE MICROANALYSIS *

Kurt F. J. Heinrich

Spectrochemical Analysis Section

Analytical Chemistry Division

Institute for Materials Research

National Bureau of Standards

Washington, D. C. 20234

\section{INTRODUCTION}

The static electron probe microanalyzer, as developed by Castaing [1] in Guinier's laboratory, can be considered a highly specialized $x$-ray spectrograph. The primary purpose of this instrument is the spectrochemical analysis of microscopic regions of a specimen. In accordance with the observations of Moseley [2], the atomic numbers of the target components (excepting hydrogen and helium) can be determined by observing the wavelengths of their characteristic $x$-ray emission lines. The intensities of the lines are related to the local concentrations of the components $[3,4,5]$. To limit the dimensions of the volume which emits radiation, a well-focused beam of electrons is used for x-ray excitation. The depth of penetration of the electrons is controlled by their energy. As the penetrating electrons spread laterally as well as in depth, the smallest effective beam size, or lateral resolution, is also related to the initial beam energy, i.e., the accelerating voltage.

The focusing of the electron beam is achieved by the well-known principles of electron optics [6]. The amount of energy that can be compressed into a narrow electron beam is

\footnotetext{
* Presented at the 69th Annual Meeting, ASTM, Atlantic C1ty, N. J., June 1966; to be published in an ASTM Special Technical Publication.
} 
Iimited hence the intensity of $x$-rays that can be produced is also subject to stringent limitations. A relatively high efficiency of $x$-ray collection in the spectrometer is therefore desirable. Such an efficiency, coupled with wavelength resolution sufficient for spectrochemical analysis, is achieved by the use of focusing bent and ground crystals, according to Johannson [7]. Bent but not ground crystals (e.g. mica) can also be used in the arrangement described by Johann $[8,9]$.

Shortly after the publication of Castaing's thesis, an instrument quite similar to Castaing's was described by Borovski1 [10]. It is interesting to note that Borovski1's illustration of his instrument shows the electron optical column mounted on a movable arm of the (fixed) spectrometer. Such an arrangement does not seem to be advantageous from a design standpoint; it shows, however, that Borovskil considered the electron optical column as an accessory to his spectrometer. This concept also determined the type of investigations performed in the USSR in the earlier years with this instrument.

An electron optical system similar to that of Castaing's instrument was employed in von Ardenne's scanning electron microscope, developed in the late thirties [11]. The purpose of this instrument is, however, quite different: a focused beam of electrons is made to scan in a raster fashion over the surface of a specimen. A detector of secondary electrons receives a signal, the intensity of which varies during the scan as a function of the specimen surface topography. This signal can be used to modulate the brightness of an oscilloscope beam scanning in synchronism with the electron beam of the microscope. Hence, a magnified image of the scanned specimen area appears on the oscilloscope screen. In comparison with transmission electron microscopy, this method offers the advantage that replica techniques or thinning the 
specimen to transparency (to electrons) are not required. The practical limit of resolution is on the order of hundreds of angstroms.

It is thus considerably poorer than that obtainable with the transmission method, although better by a factor of about 100 than that of electron probe microanalysis. In spite of the poorer resolution, this technique was further developed and found useful for diverse applications $[12,13]$.

Cosslett and Duncumb [14] demonstrated that the basic features of the scanning electron microscope can be incorporated into the design of an electron probe microanalyzer. An instrument containing these combined characteristics is called a scanning electron probe microanalyzer. The additions to a static analyzer are those of a scanning (beam deflecting) system and of an oscilloscope for observation and photographic recording of scan images. These features can be added to the static microprobe without limiting its normal operating characteristics in any way. The resulting instrument has all the capabilities of a static microprobe, and the essential elements of a scanning electron microscope. Most present-day microprobes do not have a beam as narrow as that of a typical scanning electron microscope, and only a few are equipped for detection of secondary (Iow energy) electrons. Their performance as an electron microscope is thus somewhat limited, particularly with respect to resolution. On the other hand, the combination of scanning and $x$-ray detection gives rise to an entirely new function, namely scanning $x$-ray microscopy (f1gure 1).

The range of techniques feasible with such an instrument is indeed unusually broad. This versatility cannot be fully exploited unless the operator keeps in mind that his instrument is a microscope as well as a spectrochemical analyzer. To clarify this point it is now necessary to describe in more detall the scanning electron microscope. 

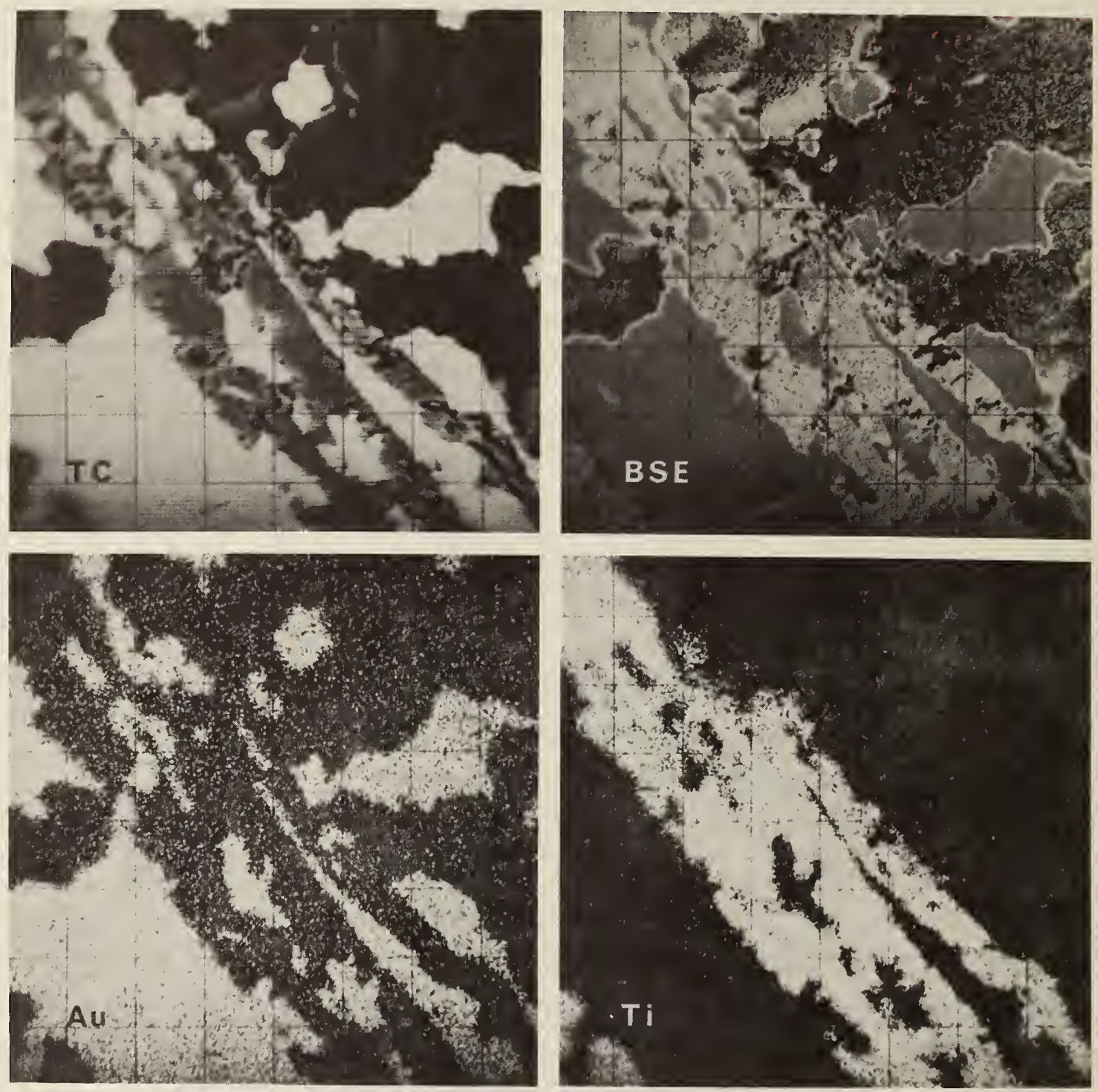

Figure 1. Scanning images of gold ore specimen. Upper left: target current image. Upper right: electron backscattering 1mage. Lower left: $\mathrm{Au} L \mathrm{La}_{1}$ image. Lower right: T1 $\mathrm{K} \alpha$ image. Instrumental cond1t1ons: $20 \mathrm{keV}$, specimen current: $5 \times 10^{-0}$ amp. Scanned area: $240 \mu \times 240 \mu$. 
2. SCANNING ELECTRON MICROSCOPY

The basic features of the electron optical systems used in both instruments for demagnification of the cathode spot image are identical. To obtain, however, electron beams of a diameter smaller than $0.1 \mu$, the two lenses commonly used in microprobes are insufficient. Since the addition of a third lens to the system represents a major change, this step has not been taken as yet in the instruments that are commercially manufactured. Indeed, as long as electron microscopy is merely considered subservient to x-ray emission techniques, it could be argued that it is not particularly advantageous to push the electron image resolution much beyond that of the $x$-ray technique. Yet, considerable effort is made to reduce the effective volume of $x$-ray emission by using softer $x-r a y$ lines [15], lower accelerating voltages [16], and thinner specimens [17]. Backscattered electrons are also used for quantitative analysis, with somewhat improved resolution [18]. Finally, the analyst who is receptive to the possibilities of scanning electron microscopy soon realizes the independent merits of this technique. It must, therefore, be expected that future scanning electron probes will be provided with electron optics of higher resolution.

Resolution, however, depends not only upon the dimensions of the electron beam but also upon the spread of the electrons within the target and upon the choice of signal used for image formation. An energy analysis of the electrons re-emitted from the target [19] reveals the presence of two distinct fractions. The fraction of the primary electrons which is re-emitted from the target after one or several collisions with the target atoms is called backscattered electrons. Electrons of much lower energy are ejected as a consequence of diverse processes such as primary and fluorescent Ionization and the Auger phenomenon. [20] These low energy electrons are called secondary electrons. 
Backscattered electrons have energies of the order of magnitude of those forming the primary beam hence, they can be detected with relatively simple devices, especially at primary energies of $20 \mathrm{keV}$ or higher. However, most of these electrons have reached considerable depths within the specimen (up to more than one micron) before re-emerging, so that the inherent lack of resolution of backscatter images would render them useless for work with very fine beams. Besides, even at the relatively high currents employed in electron microprobes $\left(10^{-7}-10^{-8}\right.$ amp for instruments having efficient $x-r a y$ detection systems), the amount of electrons reaching the typical backscatter detector is not very high, so that grainy images may be obtained.

The amount of backscattered electrons emitted in a direction towards the detector depends upon the angles between the primary beam, the specimen surface, and the direction of emergence. Consequently the intensity of the signal varies with the specimen topography (figure 2). This effect causes a particularly rich contrast when shadow effects are produced by cracks, holes, or protruding features or when the detector is located at an acute angle with respect to the specimen surface. Backscattering is also to a great extent a function of the atomic number of the target components (figure 1 ). The fraction of primary electrons re-emitted by a target of low atomic number, such as beryllium or boron, is close to zero, while elements of high atomic number backscatter as many as half of the impinging electrons [18]. This compositional effect on backscatter can produce useful contrast in flat surfaces; the dual source of variations in backscattering may also complicate the interpretation of backscatter images.

While the amount of backscatter of a given target material is nearly independent of the acceleration voltage [21], the relative amount of secondary electron emission (of 

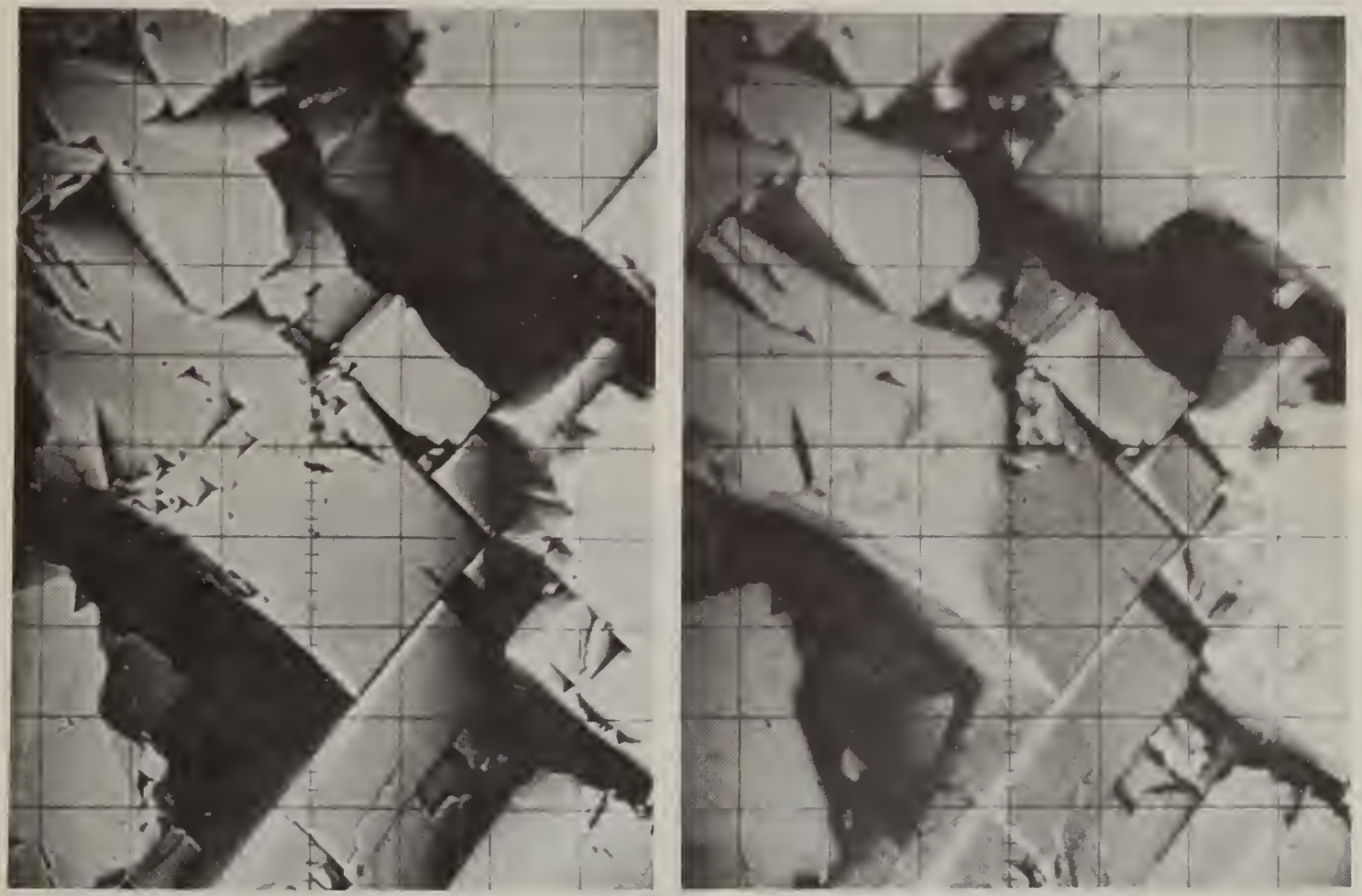

Figure 2. Topographic effects on target current image (left) and backscatter image (right).

Specimen: fractured surface of galena. Instrumental conditions: $20 \mathrm{keV}$, target current: $5 \times 10^{-8}$ amp. Scanned area: $400 \mu \times 480 \mu$. 
energies below $50 \mathrm{eV}$ ) increases rapidly at lower energy levels of primary acceleration. Furthermore, secondary electrons emitted through a wide solid angle can be collected by electrostatic or magnetic devices. Hence, at the low beam currents employed for high resolution scanning electron microscopy $\left(10^{-10}-10^{-11} \mathrm{amp}\right)$ the use of secondary electrons is more favorable from a statistical point of view. Secondary electrons are produced at the specimen surface, or very close to it, so that they can form images of high resolution. For these reasons, secondary electrons are employed extensively in scanning electron microscopy. Although their detection requires more sophisticated techniques, the superior quality of the images they produce w1ll assure their increased use even where highest resolution is not necessary (figure 3). The possibility of operating with low beam currents has the additional advantage that the destruction of delicate specimens by heat and radiation is minimized. This is particularly important when organic specimens are investigated.

The intensity of secondary emission is a function of the specimen composition, although the dependence is more complicated than in the case of backscattered electrons. Due to the low energy level of the secondary electrons, their intensity is particularly sensitive to local charges which may exist at the specimen surface.

A simple way of obtaining a signal for image formation is to isolate the specimen from ground and observe the variations of the current flowing from the target to ground during the scanning process (target or specimen current, figures $1,2,4,8,10,11,13-15)$. As this current is of the order of magnitude of the beam current, the noise and the graininess of the image are conveniently low. It must be recognized, however, that the nature of this signal is somewhat complex $[18,19]$. At higher beam energies, the predominant factor in 

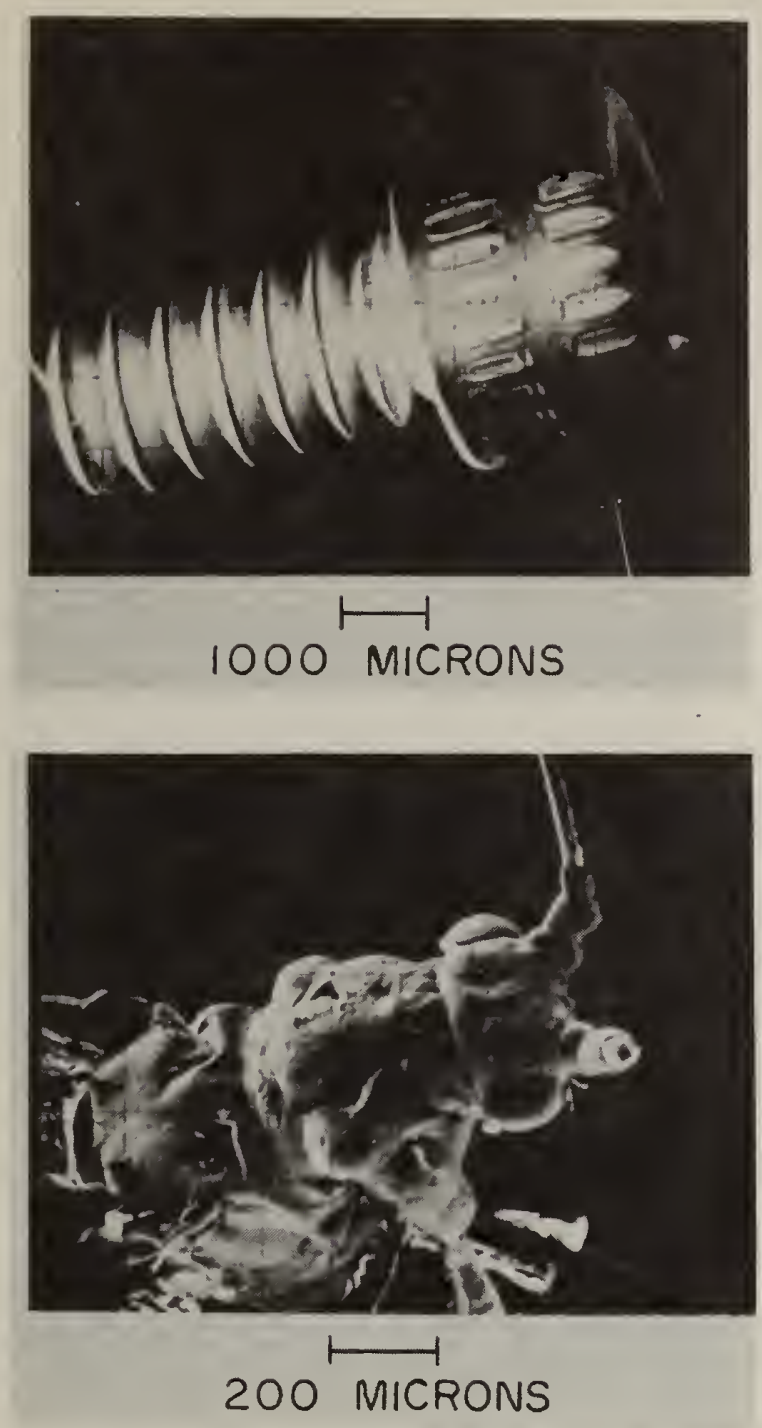
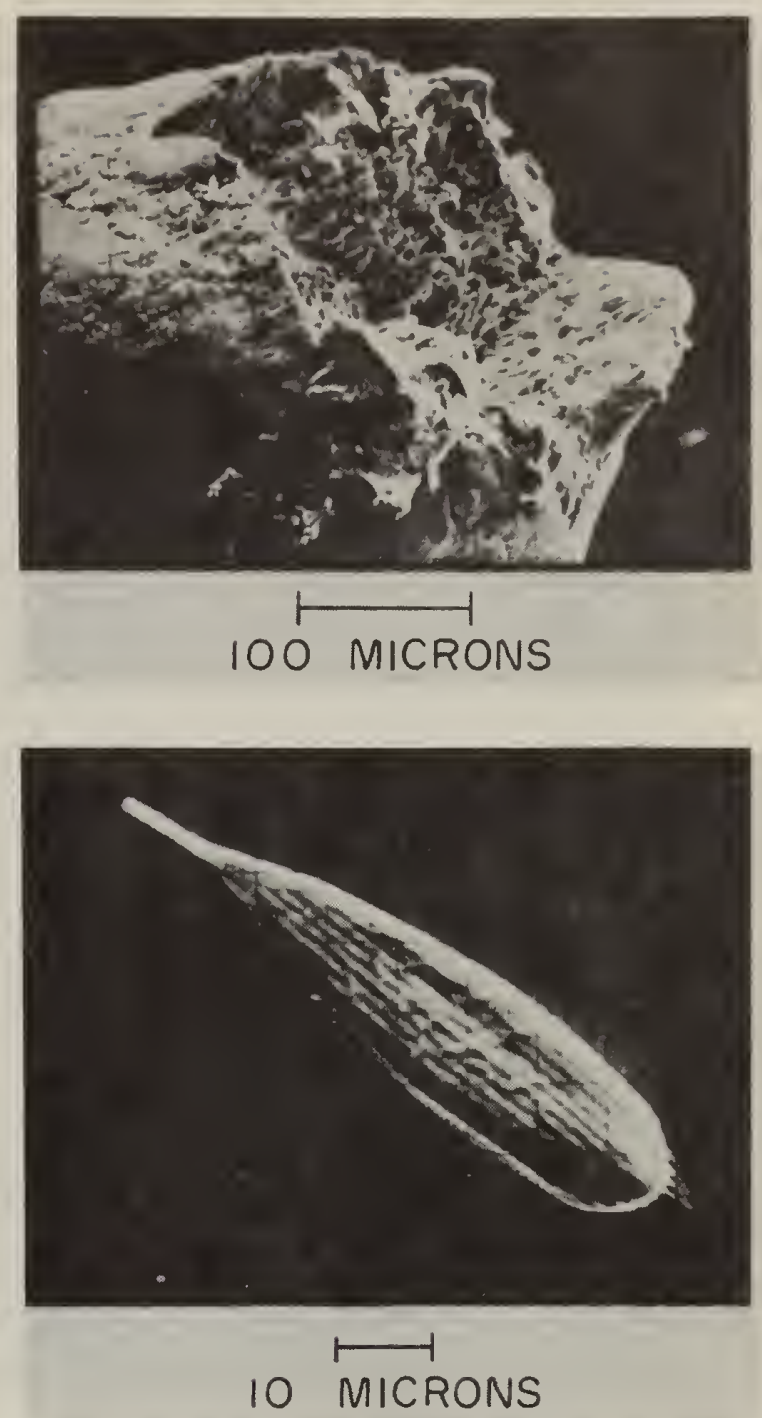

Figure 3. Secondary electron 1mages. Upper left: machine screw. Upper right: tension break of a wire. Lower left: Insect. Lower right: diatom.

Courtesy of Applied Research Laboratories, Inc. 
the variation of target current is the electron backscattering, and in favorable cases the measurement of target current can be used to quantitatively determine the amount of backscattering [18]. As the accelerating voltage is lowered, the effect of secondary emission becomes more important. Electrons other than those of the primary beam, emitted by diverse parts of the instrument, contribute as a rule to the target current. At low primary energies, the increase of secondary emission and its variation with small changes of specimen charge may establish a self-regulating system, so that drainage of the target current to ground becomes unnecessary. In such a case, the specimen need not be electrically conductive. The usefulness of the target current as an image former is therefore greatest at the relatively high primary energies $(5-30 \mathrm{keV})$ currently used in electron probe analysis.

Perhaps the most striking quality of scanning electron micrographs is their "Iifelikeness." The nature of such images is much closer to that of macroscopic vision of objects than in the case of transmission methods such as light or electron transmission microscopy or x-ray radiography. Another impressive advantage of this method, particularly at high magnifications, is the great depth of focus (figure 4 ). It is also useful in practice that the magnification can be changed continuously and over a very wide range (by a factor of $10^{3}$ ). Except where color perception is important, an efficient scanning system using secondary electron detection and a wide range of magnification could replace in many instances the rather imperfect light optics now used in many microprobes.

The raster movement of the electron beam with respect to the specimen can be achieved by electrostatic or electromagnetic beam deflection, or by mechanical displacement of the specimen. While electrostatic systems are frequently used because of their simplicity, electromagnetic systems are 
OPTICAL PHOTOMICROGRAPH X250

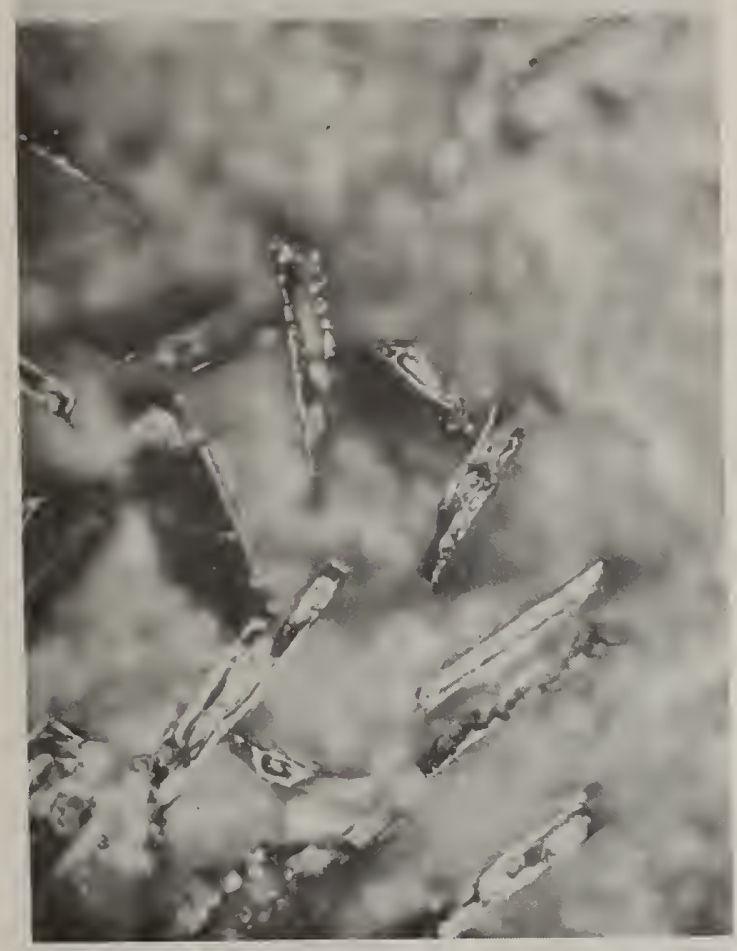

TARGET CURRENT

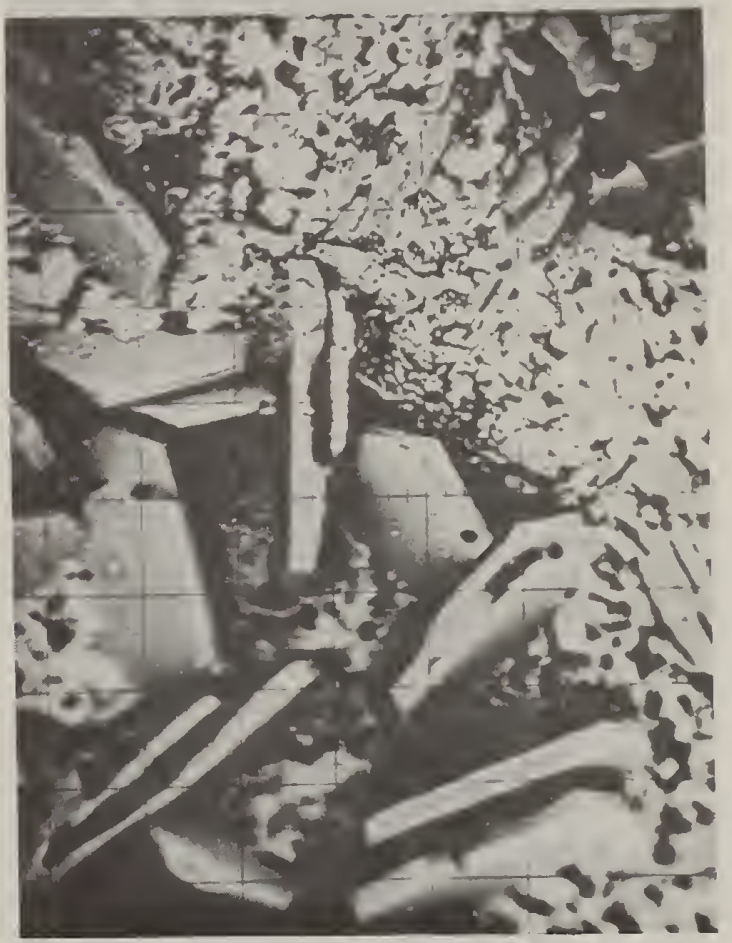

Figure 4. Micro images of recrystallized dental alloy. Photomicrograph (left) and target current image (right). Instrumental conditions: $20 \mathrm{keV}, 5 \times 10^{-8} \mathrm{amp}$. Scanned area: $550 \mu \times 440 \mu$. 
less susceptible to accidental misalignment. Furthermore, their insertion in the electron beam column presents fewer design problems. Mechanical displacement of the specimen was used in von Ardenne's microscope [11]. This idea was also applied to the scanning version of the French CAMECA microprobe [22], in order to avoid defocusing of the x-ray optics due to beam displacement.

It greatly aids the observation of the specimen if the scanning operation can be performed at such a speed as to obtain a continuous image on the oscilloscope screen. Such a system has been introduced recently in several commercial instruments. It requires detectors and electronic systems capable of rapid changes, and intense signals are needed to reduce noise effects at these high scanning rates. This renders such a system ineffective for high resolution scanning. It should be possible instead to use a memory system in which the information is scanned at relatively low speed, stored during operation, and displayed at a high speed such as employed in television systems.

The use of secondary electron or target current scans offers several interesting applications. Since the emission of secondary electrons varies greatly with minor variations of local electrical potential, secondary electron images of semiconductor devices can be used to map out the voltage distribution on the surface of such devices (figure 5), $[12,23]$. Lander et al. [24] described the observation of imperfections or dislocations by a target current technique. Dorsey [25] showed that the deflection of low energy electrons by magnetic fields can be used to register two-dimensional images of recordings on magnetic tape, using a differential secondary electron detector. Among other means of representation he uses the "deflection modulation display" previously employed by Everhart (see [25]). This technique of display was also applied to the combined recording of 


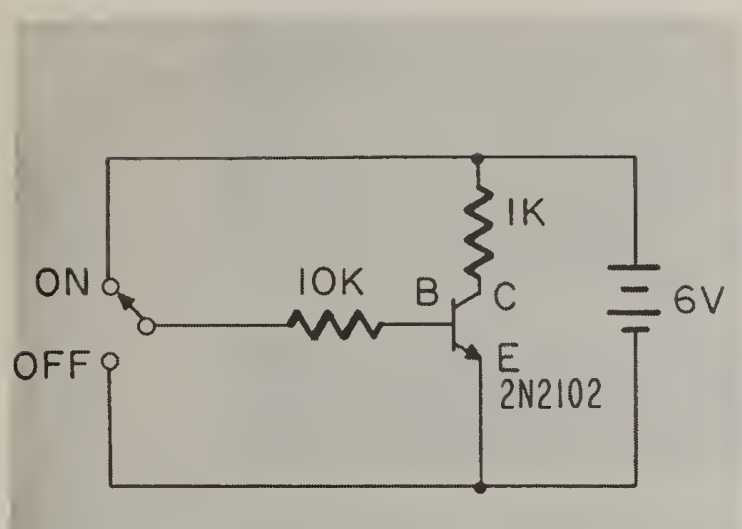

(A) SCHEMATIC

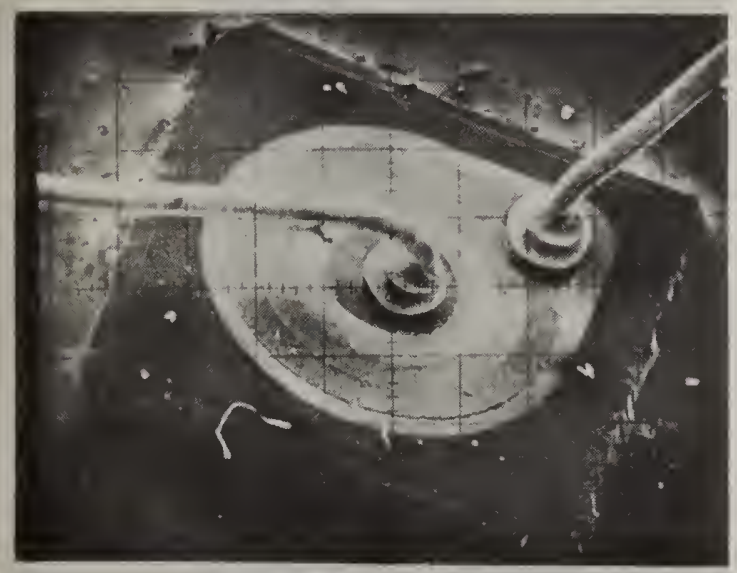

(C) TRANSISTOR OFF

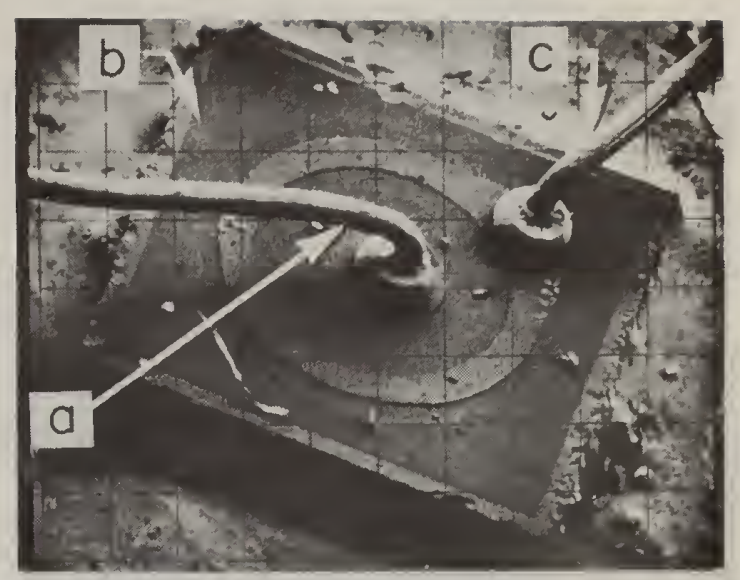

(B) ALL TERMINALS GROUNDED

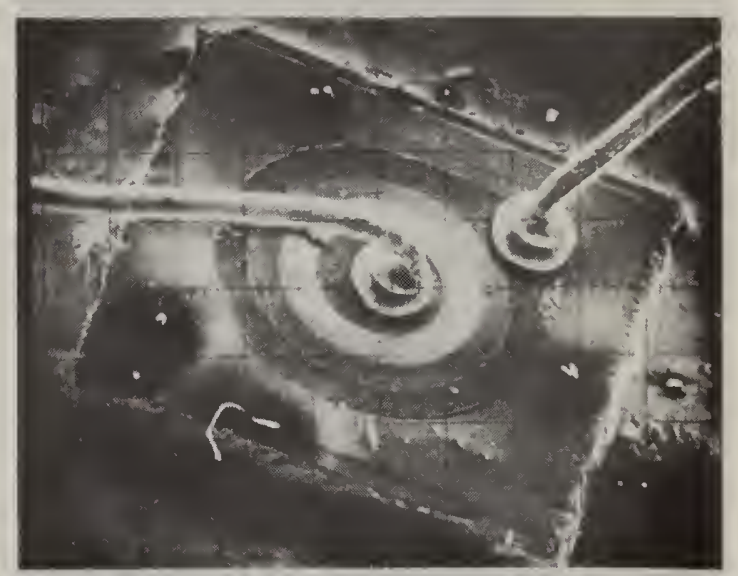

(D) TRANSISTOR ON

Figure 5. Secondary electron images of a transistor under various biasing conditions. 
backscatter and secondary electrons, yielding information concerning the composition of the specimen surface (figure 6).

\section{SCANNING $\mathrm{X}-\mathrm{RAY}$ IMAGES}

The combination of the area scanning technique with $x$-ray detection produces $\mathrm{x}$-ray area scan images. It is this type of representation that motivated the development of the scanning electron probe microanalyzer, and that is most frequently obtained with such an instrument. The speed at which this technique provides information concerning the distribution of an element over a microscopic area is of great practical importance. While $\mathrm{x}$-ray area scans may be preliminary to the quantitative analysis of selected spots, in many cases they yield all of the information that is needed. A metallurgist may, for instance, request the identification of a precipitate, an inclusion, or an oxide phase formed within a crack. He is interested in such cases in local variations rather than in exact values of elemental concentration thus, his requirements are best met by using the microanalyzer as a scanning $x-r a y$ microscope. Failure to take full advantage of this technique will result in a considerable waste of time. A demonstration of the scanning technique to the person requesting the analysis, and insistence that the microprobe operator, rather than the requester, determine the technique to be applied to the solution of a particular problem, will be of great aid in establishing an efficient service program.

\section{THE PULSE RECORDING X-RAY IMAGE}

The most common $x-r a y$ area scanning technique is shown schematically in figure $7(\mathrm{~A})$. A focusing $x$-ray spectrometer is tuned to a characteristic line of the element under investigation. The pulses produced in the detector are amplified and used to modulate the beam brightness of an oscilloscope scanning in synchronism with the microprobe. Thus, each detected photon produces a dot of light on the 

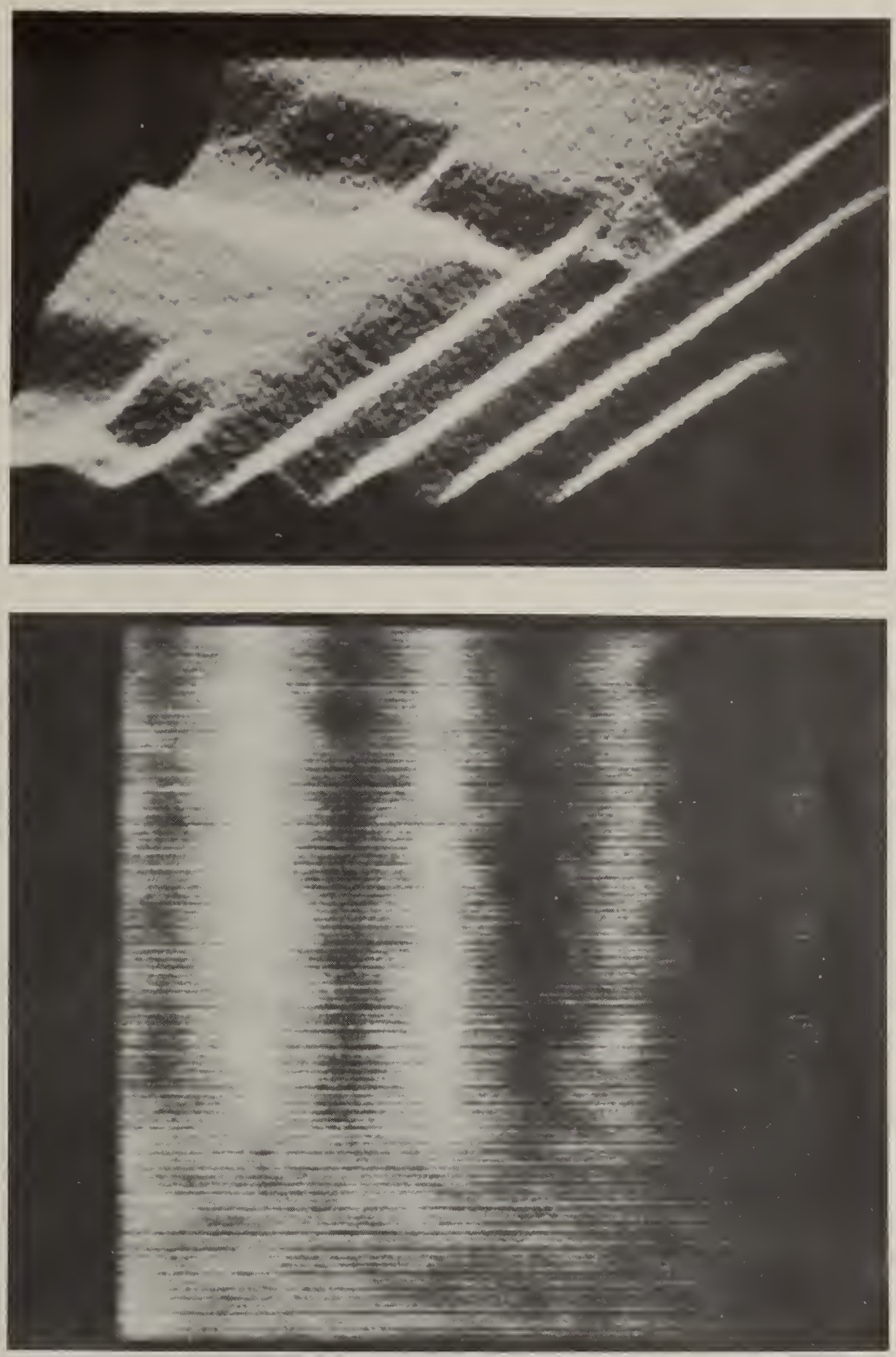

Figure 6. Combined recording of secondary and backscattered electrons from a thin film magnetic memory plane, with "deflection modulation display" (top), and secondary electron recording of the edge of a magnetic track (bottom). Acceleration voltage: $20 \mathrm{keV}$. Area scanned: $1 \mathrm{~mm} \times 1 \mathrm{~mm}$. Courtesy of J. R. Dorsey. 
(A)
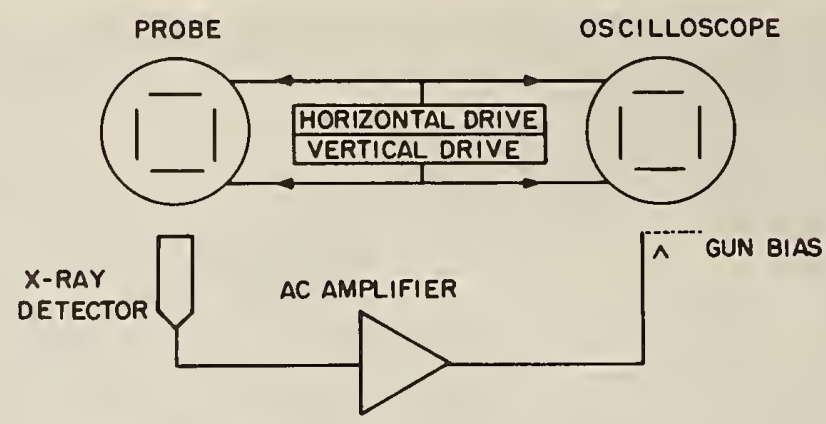

(B)

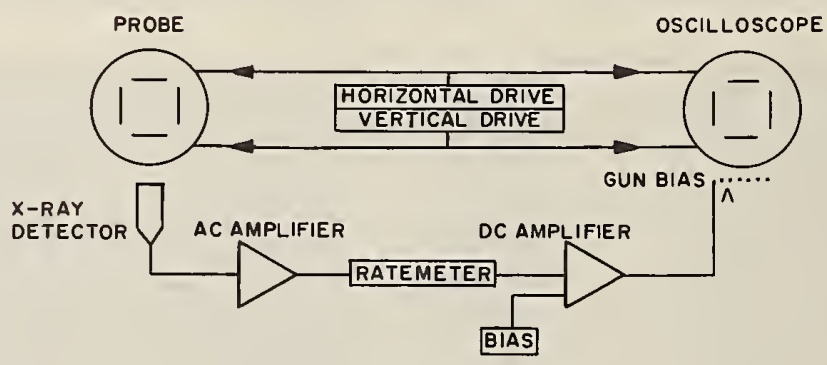

(C)

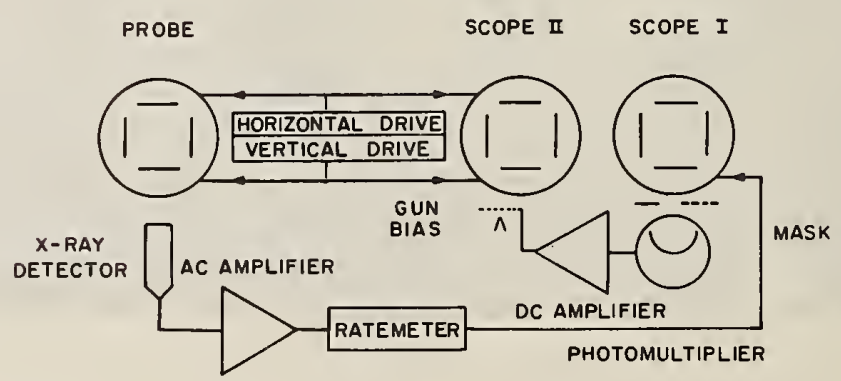

Figure 7. Schematic diagrams of (A), pulse recordings (B), expanded contrast scanning and (C), concentration mapping. 
oscilloscope screen. A photographic camera records these dots of light, and the sum of the dots recorded during the exposure forms the scanning image. We will call this method the pulse recording method (figures $1,8,9,10,11,13$ ).

The effect on the scanning image of the statistics of random photon arrival has already been mentioned. The statistical "noise" superposed upon the information may adversely affect the image quality by producing granular texture. This impairs the comparison of shades (1.e., signal intensity). Furthermore, it also reduces the definition of contours (figure 8). It is good practice to control the statistical factor by using a scaler to count the photons collected for the scan; several frames are thus recorded until the desired number of photons is registered. This is also helpful in controlling the total brightness of scanning pictures, provided that some control is exerted upon the brightness of a single light dot. It is, however, impossible to set a fixed rule concerning the minimum number of photons to be accumulated. The author uses, under average conditions, 200,000 counts per exposure. This number can be reduced when the element under investigation is present in small localized areas, and should be increased if it extends over most of the surface, if a complex structure or small concentration changes must be illustrated, or when the signal to be observed is close to the background level. In order to avold overexposure of the photograph, the brightness of the individual photon signal must be varied inversely to the number of photons per area unit at the brightest level.

When low concentrations are registered, the existence of background, chlefly due to continuous radiation, is quite bothersome. This is particularly true if the specimen contains areas of varying mean atomic number, and if the wavelength of the observed line is short $(<I \AA)$. As the intensity of continuous radiation varies markedly with the mean atomic 

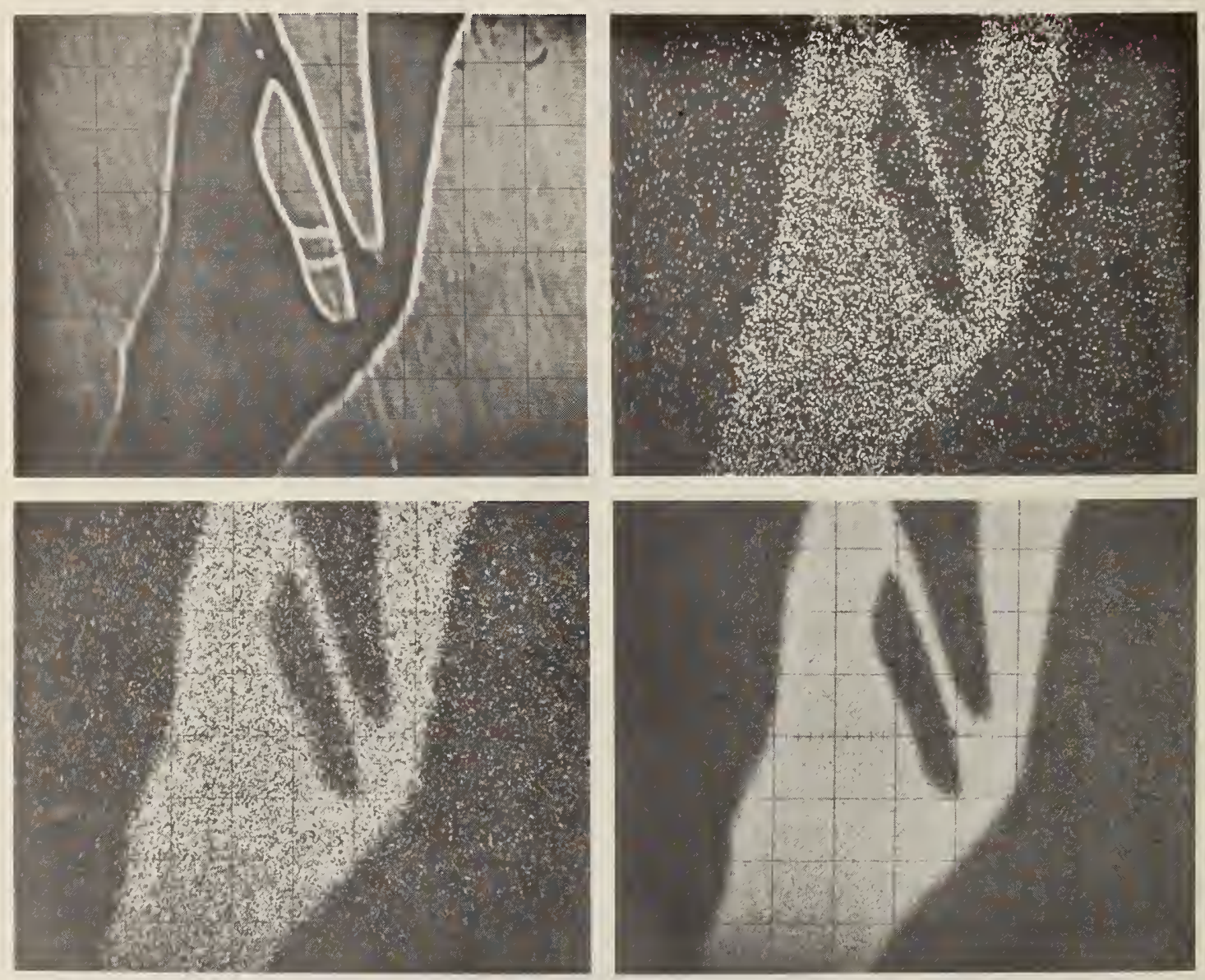

F1gure 8. Effect of number of accumulated $x-$ ray photons. Tazewe11 meteorite. Upper left: current image. Upper right: $\mathrm{N1} \mathrm{Ka}, 20,000 \mathrm{cts}$. Lower left:

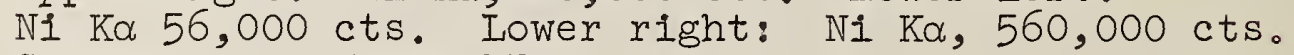
Scanned area $70 \mu \times 55 \mu$. 
number of the target, variations in background intensity may then simulate or mask low concentrations of the element to be investigated. In quantitative analysis this background contribution is determined separately and subtracted from the observed signal intensity. An analogous correction procedure cannot be applied to the $x$-ray pulse recording method; hence a high line-to-background ratio is very desirable when this scanning technique is performed. The use of narrow detector slits, and of pulse height selection, and the avoldance of analytical lines of short wavelength, help to minimize the background effects.

The magnification of the image obtained in the scanning procedure is determined by the ratio of the deflections on the oscilloscope screen to those on the specimen; this ratio can be made as high as wanted. The useful magnification is, however, determined by the spatial resolution of the technique. The effective excited volume of the specimen under typical conditions has a diameter of 2-3 microns. To obtain images of reasonable sharpness, this distance should be represented by no more than 1-2 mm on the 1mages. Therefore, magnifications of more than 500-1000 are hardly justified. This corresponds, for the conventional 8-cm oscllloscope screen, to a minimum scanning area of 80-160 microns diameter.

The excited volume diminishes when the operating voltage is reduced [16] (figure 9). The minimum excitation potential of the characteristic line sets a limit to this approach; improved resolution can sometimes be achieved by switching to lines of longer wavelength, which can be exclted at lower potentials [15].

If quantitative analysis is to be performed, it is important to prepare the surface to be analyzed to a high degree of flatness. For qualitative purposes, however, this precaution is frequently unnecessary, as illustrated in figure 10. The inspection of specimens as received permits 

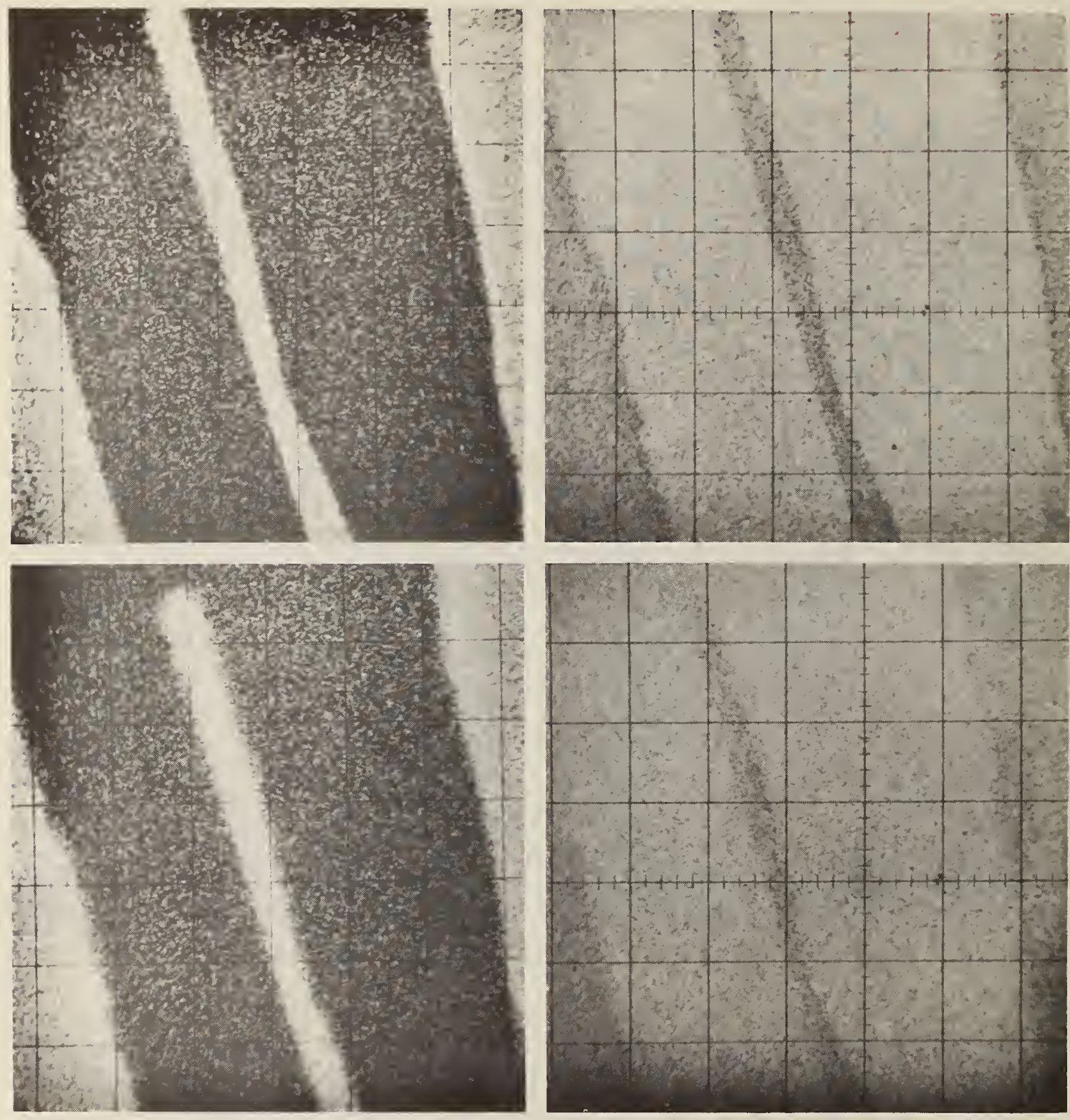

Figure 9. Effect of electron beam energy. Tazewell meteorite. $\mathrm{Ni} \mathrm{Ka}$ (left) and $\mathrm{Fe} \mathrm{K \alpha}$ (right) area scanning images.

Acceleration voltage: $20 \mathrm{keV}$ (above) and $40 \mathrm{keV}$ (below).

Scanned area: $192 \mu \times 192 \mu$. 


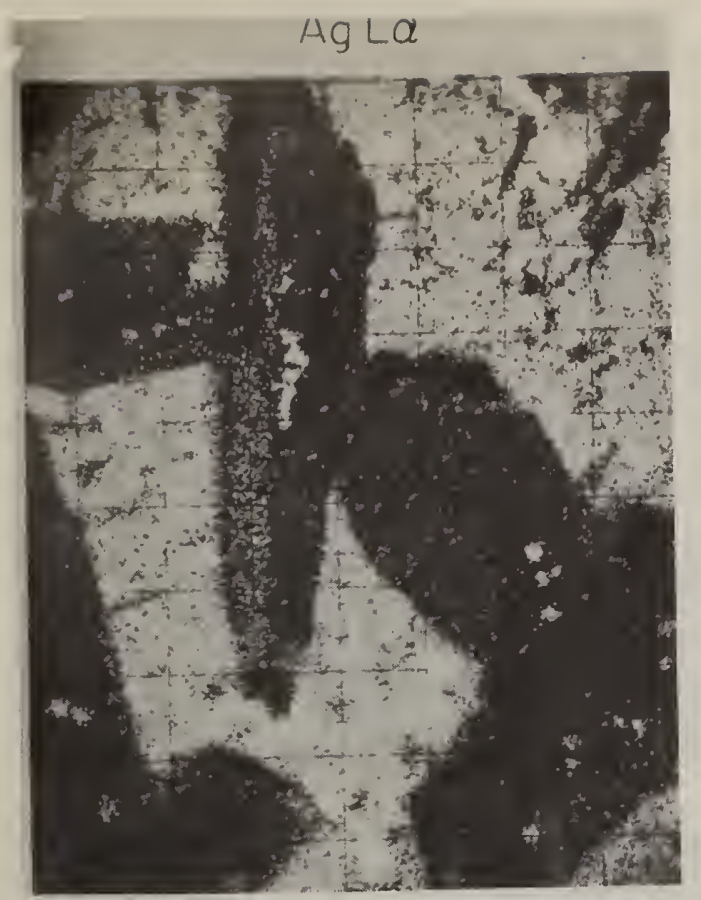

$\mathrm{Hg} \mathrm{Ma}$
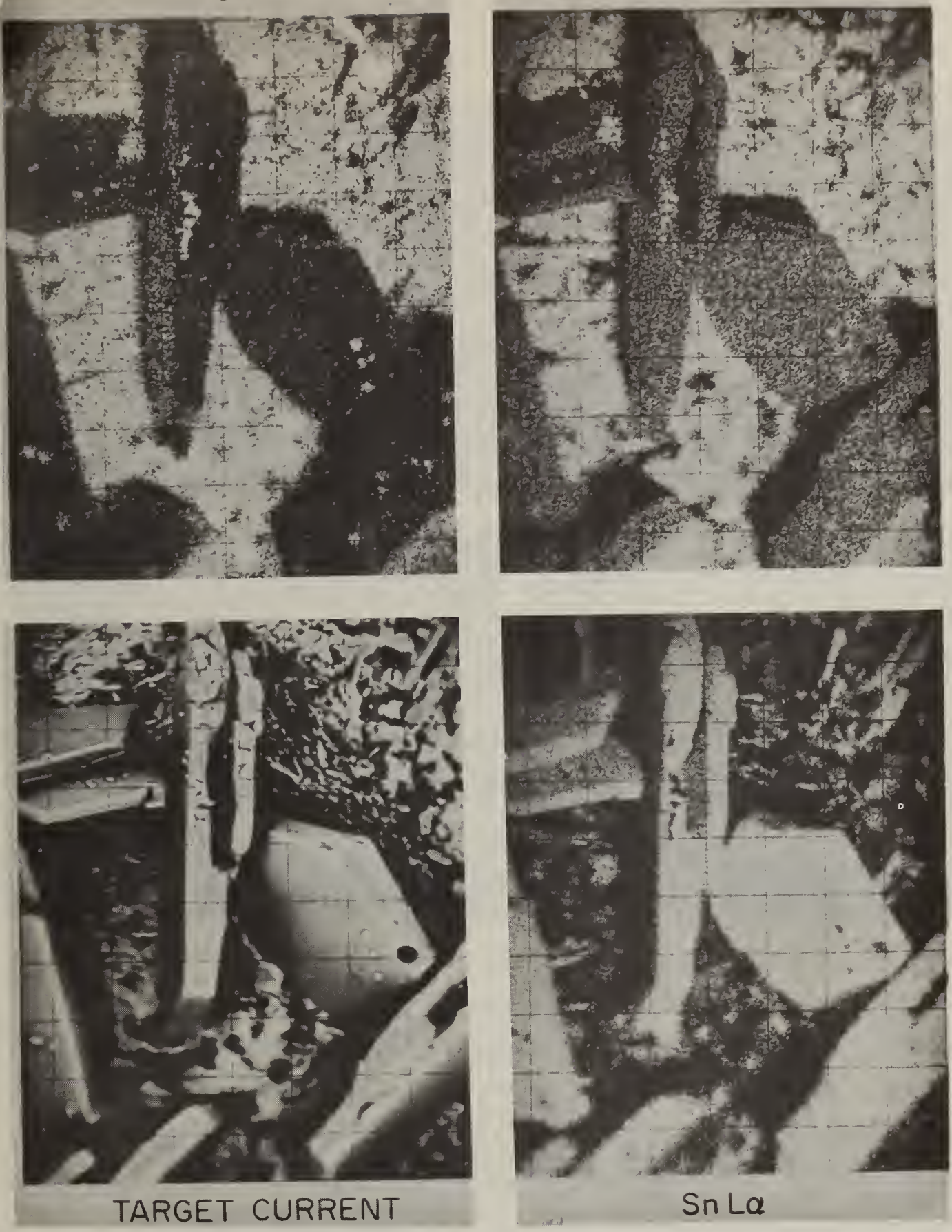

Figure 10. Recrystallized dental alloy, unprepared surface. Same focus and conditions as figure 4. Upper left: $\mathrm{Ag} L \alpha$ x-ray scan. Upper right: $\mathrm{Hg}$ Ma $\mathrm{x}$-ray scan. Lower left: target current scan. Lower right: Sn La $\mathrm{x}$-ray scan. Aréa scanned: $275 \mu \times 220 \mu$. 
the identification of features located at the specimen surfaces which could be destroyed by the conventional techniques of specimen preparation.

\section{THE EXPANDED CONTRAST X-RAY IMAGE}

The contrast produced by a signal which is only slightly higher than the background can be enhanced so that only signal levels above background are recorded. Melford [26] proposed and demonstrated such an "expanded contrast method" in which brightness modulation by the ratemeter signal has been employed for image formation (figure $7 \mathrm{~B}$ ). With this arrangement, an arbitrary voltage level (bias) can be subtracted from the ratemeter output so that the onset of intensity registration at the oscilloscope screen can be shifted above the background level. This method can also be used to enhance differences at high concentration levels (figure 11). A difference of $5 \%$ in the concentration of an element at the 50\% level is difficult to detect on a pulse registration image. If, instead, Melford's technique is used, and the bias is set just below the signal level for $50 \%$, the difference is easily noticed, provided that sufficient counts are collected to overcome the effects of statistical fluctuations.

The finite time constant of the ratemeter makes relatively slow scanning speeds necessary. Therefore the scan is performed in a single frame sweep. The sweeping speed, the number of lines per frame, and the ratemeter time constant must be judiciously chosen in order to avoid statistical jitter of the image brightness as well as loss of spatial resolution due to the inertia of the ratemeter output at high time constants.

\section{CONCENTRATION MAPPING}

Although the expanded contrast method permits emphasizing small changes at a high concentration level, the information obtained is comparative rather than quantitative. A more quantitative approach can be taken by using a device producing 

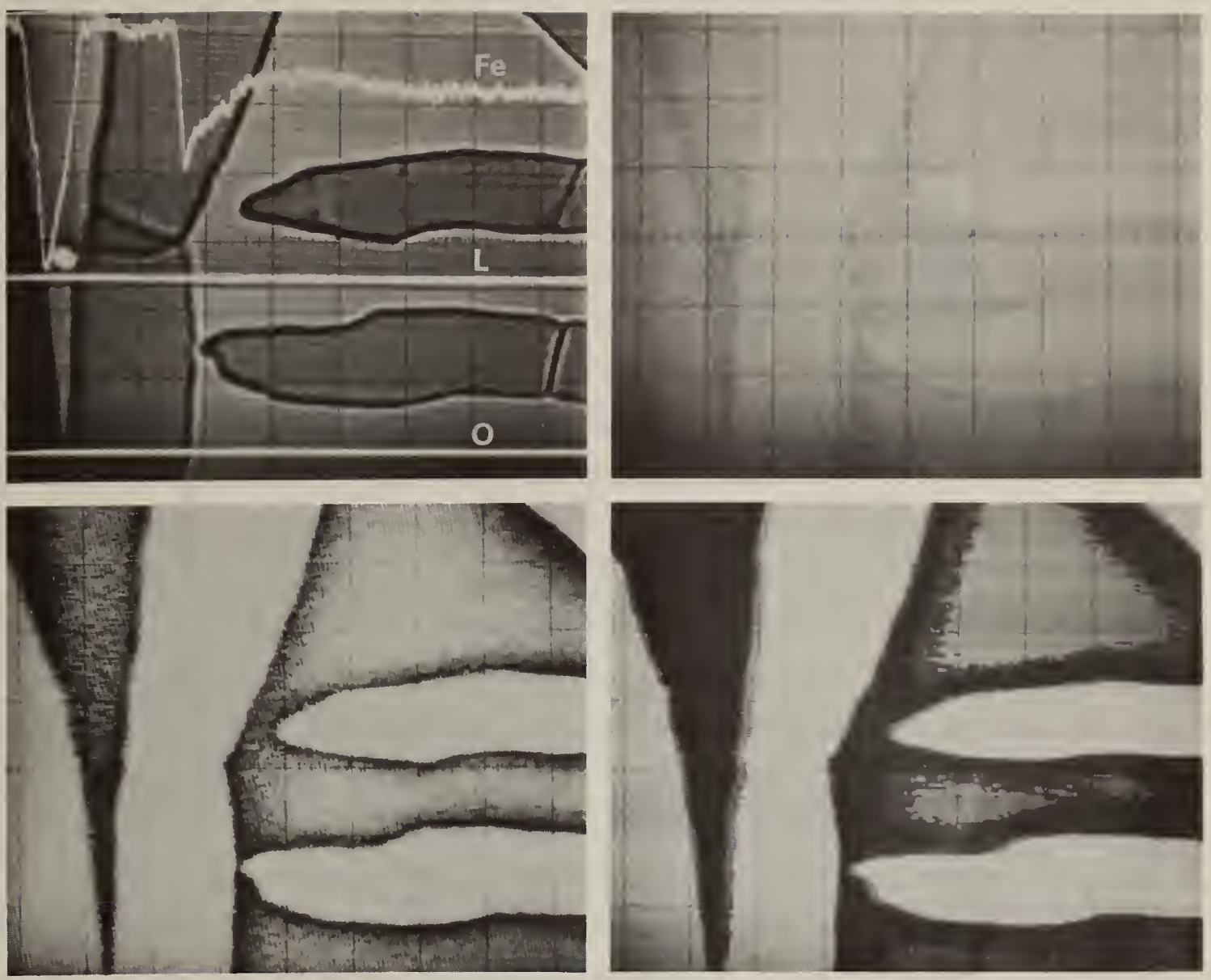

Figure 11. Tazewell meteorite: representations of the Fe Ka signal.

Upper left: x-ray line scan of $\mathrm{Fe} \mathrm{Ka,} \mathrm{(Fe),} \mathrm{and}$ zero intensity level (0), superposed upon a target current area scan. The Iine (I) marks the locus of the line scan, with respect to the target current area scan. Upper right: pulse registration $x-r a y$ area scan. Lower left: expanded contrast image. Lower right: four-level concentration map. Scanned area: $138 \mu \times 110 \mu$. 
abrupt changes of the oscilloscope beam brightness at predetermined ratemeter signal levels. The principle of this technique, called concentration mapping, is illustrated on the graph in figure 12, in which the relationship of scope beam brightness to x-ray signal intensity is schematically plotted for the pulse registration image, for the enhanced contrast $x$-ray image, and for a concentration map. It can be appreciated that in principle this method shows the location of quantitatively defined concentration ranges; to obtain this information, all concentration differences within each range must be ignored.

The first concentration maps to be obtained [27] used an auxiliary oscilloscope (not employed for image visualization) as a ratemeter output analyzer. This optical approach to concentration mapping, which is the most flexible and easiest to improvise, will 1llustrate the procedure (figure $7 C$ ). The ratemeter output deflects the beam of the auxiliary oscilloscope. Let us assume that this deflection is along the vertical screen axis. In the simplest variation of the technique, deflection along the other axis is not used. The oscilloscope beam will thus display vertically the ratemeter output voltage. The oscilloscope screen is now covered by a mask cut so that only a limited sector of the beam path remains visible to an observer in front of the oscilloscope. This observer would see the light only when the ratemeter output causes a beam deflection between two limits corresponding to well-defined concentrations of the element being investigated. Hence the appearance of light indicates that the concentration of this element at the point of impact of the electron beam is within the preselected concentration range. The observer is now replaced by a phototube, the output of which is made to modulate the signal brightness of the main oscilloscope. The beam of this main oscilloscope scans in synchronism with the electron beam on the specimen, as in the scanning techniques 


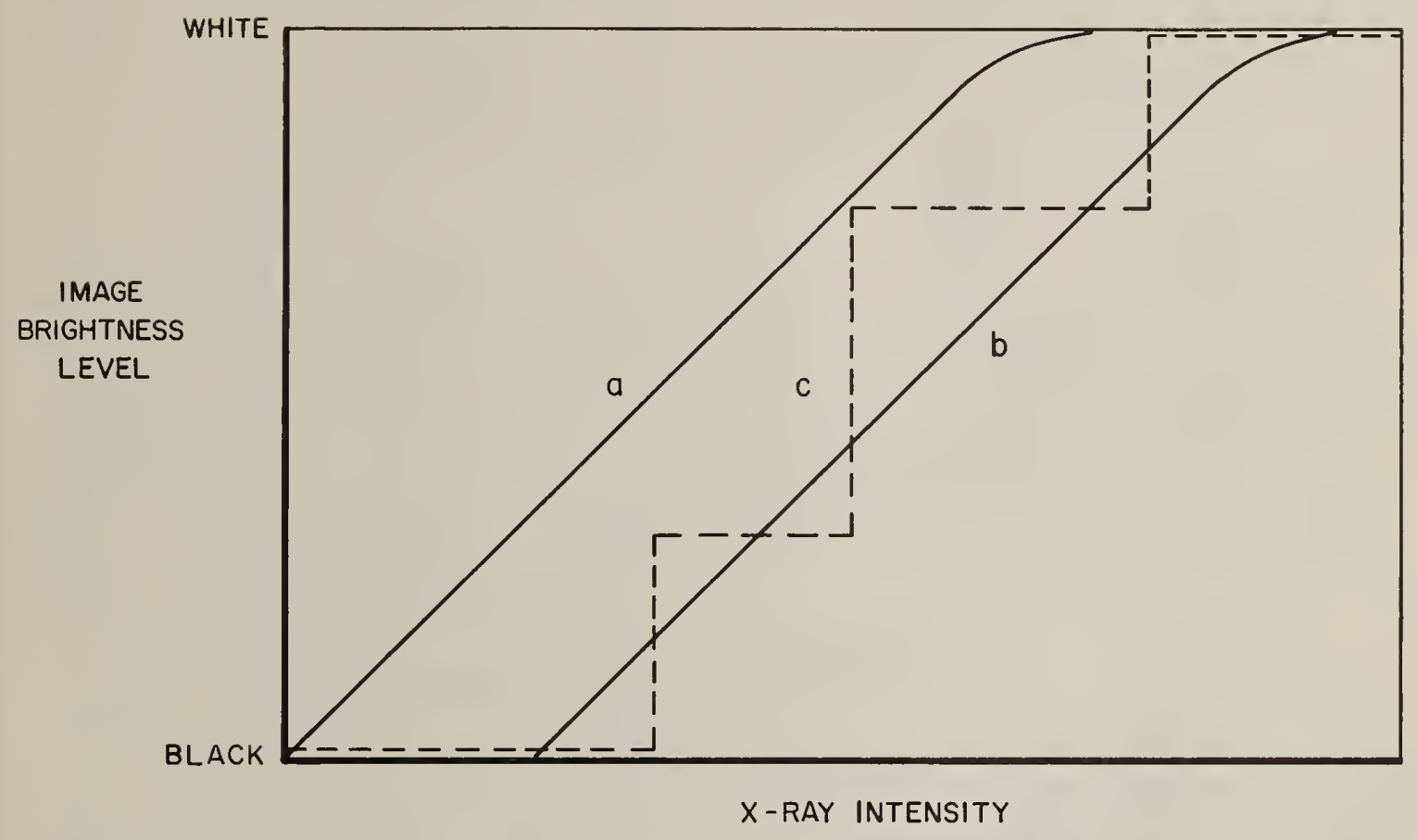

Figure 12. Oscilloscope beam brightness as a function of $x$-ray signal intensity: a. pulse registration, b. expanded contrast technique, c. four-level concentration map. 
described previously. The result of the operation is an image on which areas containing the element of interest within the preset concentration range are marked by a characteristic level of brightness.

A variation of this procedure consists in replacing the signal cutout of the mask by a series of slits. In this case, several equiconcentration lines will be produced in one operation. This is useful for specimens, such as diffusion couples, in which the lines corresponding to different levels cannot be misinterpreted.

In another variant, two partially overlapping ranges are represented by adjacent cut-outs. By means of a horizontal square-wave deflection, the beam of the auxiliary oscilloscope is made to switch periodically from one cut-out to the other. The range common to both cutwouts appears white on the concentration map, while areas cover by one cut-out only appear grey, or dotted if the square-wave-frequency is slow [27]. Interesting combinations of boundary conditions can be obtained by applying one ratemeter output to the horizontal axis of the auxiliary oscilloscope, and another ratemeter output -- corresponding to another element -- to the vertical axis. Each point on the auxiliary screen corresponds thus to a coincidence of defined concentration levels of the two elements (including absence of one or both).

The optical concentration mapping device can be replaced by an electronic equivalent [28]. The electronic concentration mapper provides an output voltage or current which is constant within several adjustable input voltage ranges, changing abruptly in passing from one range to another. The output of this device is used to modulate the brightness of the imageforming oscilloscope. The illustrations reproduced here were made using a device, constructed at the National Bureau of Standards, that can employ up to four ranges, so that images in black, white, and two grey shades can be produced. 
The application of this technique is not restricted to $x$-ray signals. With instruments capable of analysis by target current measurement [18], target current concentration maps [29] can be produced in appropriate systems, usually in much shorter time than the corresponding $x$-ray concentration maps (figure 13). These types of images can be used with advantage for quantitative metallography $[26,30,31]$.

7. QUANTITATIVE AREA SCANNING

A scanning technique capable of yielding quantitative information is of great practical interest. Its application would be of benefit in the study of subjects such as homogeneity, diffusion of elements, etc. It must be recognized, however, that a scanning procedure has limitations which affect the accuracy of the data obtained by 1t. The most important factors to be considered are:

1. counting statistics

2. defocusing of the $x$-ray optics

3. instability of excitation

4. problems of calibration

These potential sources of error must be considered before a quantitative evaluation of area scans is attempted. The importance of the statistical limitations of accuracy can be illustrated by considering the scanning image as composed of a number of discrete image elements. In order to obtain acceptable quantitative information, the effects of counting statistics must be kept within tolerable bounds for each of these elements.

As an example, we shall assume a specimen composed of three elements, all present at fairly high concentrations. The counting rates obtained on the specimen will be assumed to be on the order of 5000 counts/sec, and the background counting rates to be negligible. To obtain the counting rates at one point of the specimen with a coefficient of variation of $0.2 \%$

$$
V=\frac{\sigma \mathbb{N}}{\vec{N}}=1 / \sqrt{\mathbb{N}}=2 \times 10^{-3}
$$



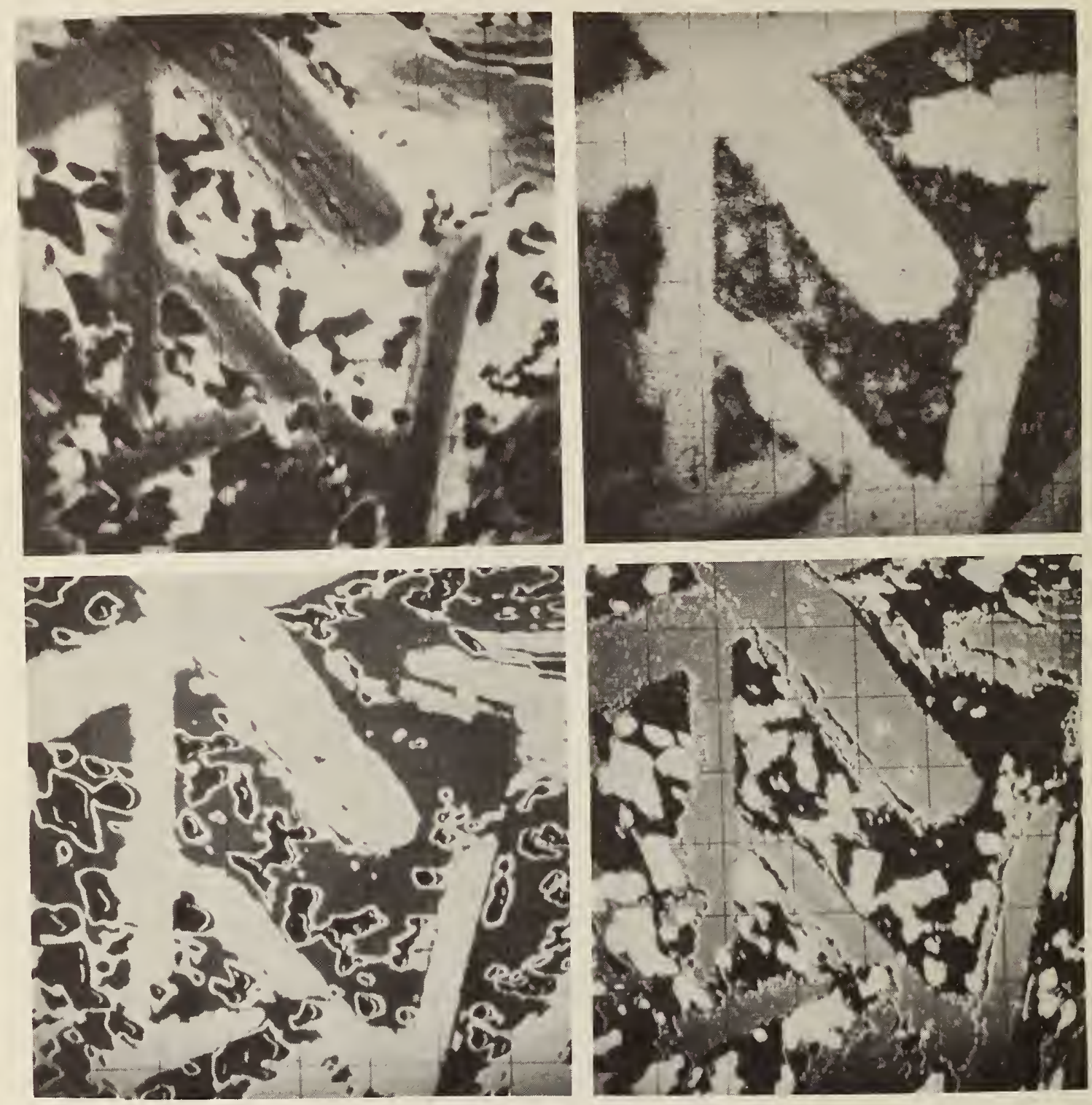

Figure 13. Dental alloy, pollshed surface.

Upper left: target current image, Upper right: Sn La, x-ray scan. Lower left: three-level conceritration map using target current signal. Lower right: same, with a different sequence of brightness values. Acceleration voltage: $30 \mathrm{keV}$. Scanned area: $132 \mu \times 132 \mu$. 
where $\overline{\mathrm{N}}$ is the average number of counts collected in one operation, we must accumulate a minimum of $2.5 \times 10^{5}$ counts/sec, for each element [32]. At the counting rate of 5000 counts/sec, 50 seconds of counting time are thus required for each point. Assuming that the same time is spent for the observation of the standard, three elements can be measured with one scaler and spectrometer in $300 \mathrm{sec}$. This can be reduced to $100 \mathrm{sec}$ if three spectrometers and scalers are available. Six numbers must be read from the scalers and recorded. The conventional correction procedures must then be applied, using slide rule, desk calculator, or electronic computation.

Let us now apply the same technique to a scanning raster of 100 lines per frame on the same specimen. For a square scan, it is reasonable to consider each line as composed of as many image elements as there are lines in the frame. Consequently, our area scan is equivalent to performing the analysis, as described above, of 10,000 points. This would require a counting time of $10^{6} \mathrm{sec}(278 \mathrm{hrs})$ for each element. A correction calculation would have to be performed with each of the 10,000 pairs of numbers generated in the operation. Due to the sheer volume of this information, it would be impossible to use it for any practical purpose without further graphical or statistical procedures.

There are several ways to abbreviate this tedious operation while preserving the part of the information which is considered significant. In the first place, the scanning procedure eliminates the need for manual translation of the beam position. The next consideration concerns the number of counts required for each point. When a group of measurements is interpreted, less statistical precision is in general needed for the individual measurement. If in our example a coefficient of variation of $10^{-2}$ were to suffice, the time for one counting operation could be reduced from $50 \mathrm{sec}$ to $2 \mathrm{sec}$. With so short a counting period, it would be unnecessary to 
repeat the standard measurements more than occasionally; we will assume that the time for standard reading can be neglected. With these assumptions the total time requirement for the complete scan is reduced to $5.6 \mathrm{hrs}$.

It is even more advantageous to increase the counting rates. This abbreviates the duration of the analysis without loss of statistical precision. If counting rates can be increased to 20,000 count/sec, the operating time is further reduced to $1.4 \mathrm{hrs}$. Finally, the duration of the analysis can be shortened by reducing the number of points. A raster of $40 \times 40$ points instead of $100 \times 100$ could be analyzed with a coefficient of variation of 0.01 , at counting rates of 20,000 counts/sec, in 13.3 minutes. This is quite a reasonable duration for such an operation, particularly when compared to the first figure of 278 hours.

At a rate of two image elements per second, manual data recording must be replaced either by graphical procedures such as the concentration mapping, or by print-out. The first alternative is preferred when a great number of points is used and the interest lies primarily in the distribution of a few concentration levels. The second procedure, in which the digital nature of the information is conserved, is particularly useful when further mathematical treatment of the data is planned. Here it is convenient to store the data obtained on the image elements in a memory device such as the data storage section of a multi-channel pulse height analyzer. The decisions concerning further processing of the data can then be postponed until all data have been gathered and inspected (figure 14 ).

In the cylindrically focusing $x$-ray spectrometers generally employed in electron probes, the point of x-ray excitation must lie on the line along which focusing occurs for the wavelength in question. This line crosses the specimen surface in vertically placed spectrometers, and intersects it in the case of horizontally arranged spectrometers. 

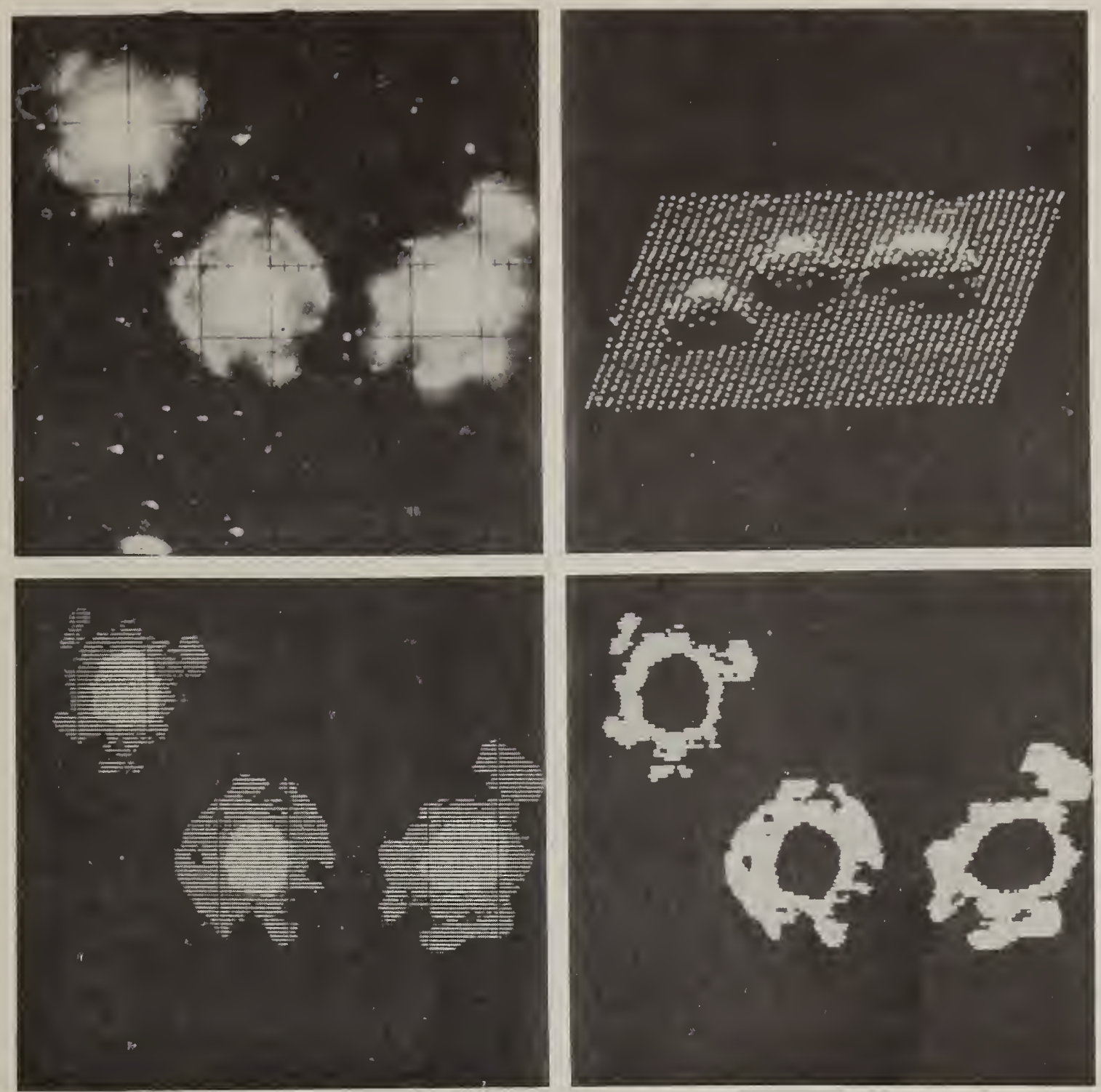
Figure 14. Diffusion in a specimen consisting of niobium wires
imbedded in tin. The phases that can be observed are niobium (wire cross-sections), $\mathrm{Nb}_{3} \mathrm{Sn}$, and $\mathrm{tin}$. Upper left: target current image. Upper right: $\mathrm{Nb} L$ emission, non-dispersively detected by a $\mathrm{Ne}$ detector and a 40 x 40 channel memory core. Both vertical position and brightness are a function of signal intensity. Lower left: Nb L radiation (non-dispersively), three position concentration map; brightness increases with the concentration of niobium. Lower right: two-level concentration map of the same signal, showing in white the distribution of the phase $\mathrm{Nb} 3 \mathrm{Sn}$. Acceleration voltage: $20 \mathrm{keV}$. Area scanned: $440 \mu \mathrm{x} 440 \mu$. 
Consequently, the observed $x$-ray intensities decrease if the beam is moved away from the focal position by horizontal displacement; in vertically arranged spectrometers, the x-ray intensities also depend critically upon the specimen position along the vertical axis.

This defocusing effect limits seriously the extent to to which $x$-ray scanning operations by beam displacement can be interpreted quantitatively [28]. In scans covering several hundred microns, even the qualitative interpretation may be affected by serious loss of signal intensity at the edges of the image. To avold errors due to this effect, the following alternatives are suggested:

1. To restrict the width of scanning (to a width of $50 \mathrm{\mu}$ or less, depending upon the spectrometer characteristics), for scanning operations which are to be quantitatively interpreted.

2. To use scanning by mechanical displacement rather than beam displacement [22]. This, however, can only be done at relatively slow speeds. It is advantageous to have capabilities for qualitative high-speed beam scan and for slow mechanical specimen scan in the case of quantitative applications.

3. To use semifocusing or non-d1spersive [28] x-ray spectrometers for extensive area scans to be evaluated quantitatively.

4. To employ signals other than $x$-rays (e.g. target current).

The variation of $x$-ray signals as a function of specimen elevation can seriously affect automatic scanning procedures with mechanical specimen translation. The control of the specimen surface elevation is, in fact, one of the most important functions of the optical microscope mounted within the electron probe.

Scanning procedures, both by specimen and by beam translation, preclude in general a frequent check of intensities by means of standard reference materials. It is therefore 
important to control the instrument stability for the duration of the scan. Some instruments permit the monitoring of a current proportional to the beam current. This permits the observation of beam fluctuations. It has also been proposed that long term beam stability can be achieved by a feedback system monitoring such a current. When stepwise scanning is performed, a direct correction for beam fluctuation can also be achieved by integrating or counting the detector pulses at each point of the specimen for fixed amounts of beam (or monitor) current rather than for fixed time. It would be inappropriate to use the target (specimen) current for this purpose, in view of its variation as a function of specimen composition and surface topography. The analyst should also consider that signal fluctuations may arise as well due to changes of detector efficiency with changes of temperature or pressure (in the case of flow detectors), or of the crystal spacing of monochromators due to thermal expansion.

\section{CATHODOLUMINESCENCE}

Besides the $x$-ray signals and those derived from backscattered and secondary electrons, the emission of light in the visible and infrared ranges can also be used to obtain information concerning the target bombarded by electrons. The intensity and spectral distribution of the cathodoluminescent emission can be affected by trace amounts of some elements. The relations between composition and emission in the visible range are, however, much more complex than those between composition and $x$-ray production, so that the use of cathodoluminescence for analytical purposes is limited to special cases which have been emplrically studied, mainly in the flelds of minerals and ceramics [33].

Cathodoluminescent emission can be recorded by color photography through the light microscope incorporated in most microprobes. It is sometimes more advantageous to apply a scanning technique similar to that used for $x$-ray signals or 
backscattered electrons [34]. In this case colors are not retalned, although colored filters can be used to advantage. The spatial resolution obtained 1s, however, excellent, as the visible radiation is generated very close to the specimen surface (figure 15).
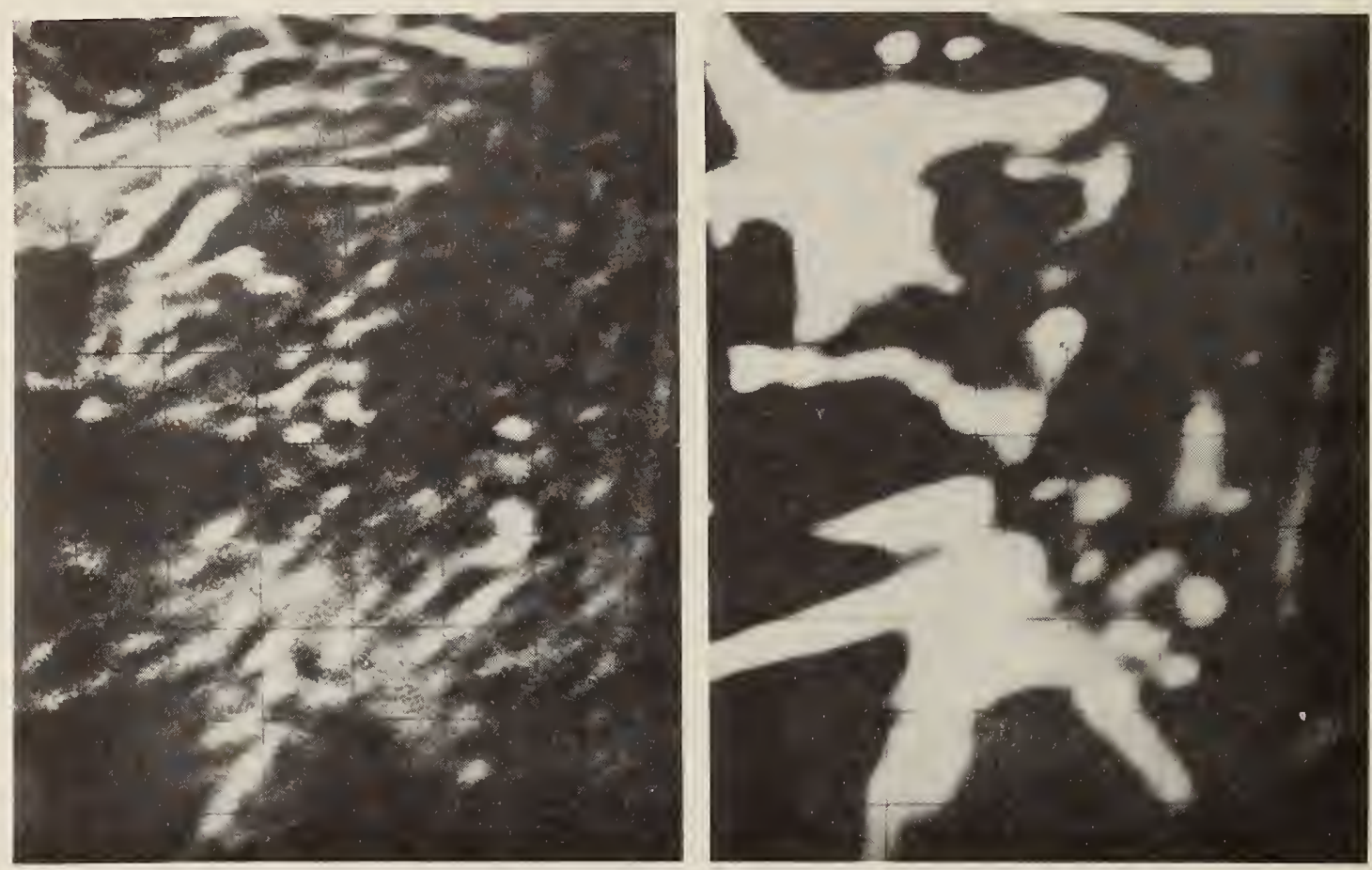

F1gure 15. Sapphire crystals imbedded in a nickel base alloy. Left: target current 1mage. Right: cathodoluminescence scanning image. Acceleration voltage: $20 \mathrm{keV}$. Scanned area: $55 \mu \times 70 \mu$.

Kyser and Wittry studied the emission of infrared cathodoluminescent emission from gallium arsenide [35,36] and showed that local intensity variations can be attributed to variations in the concentration of impurities or crystal imperfections (figure 16). 


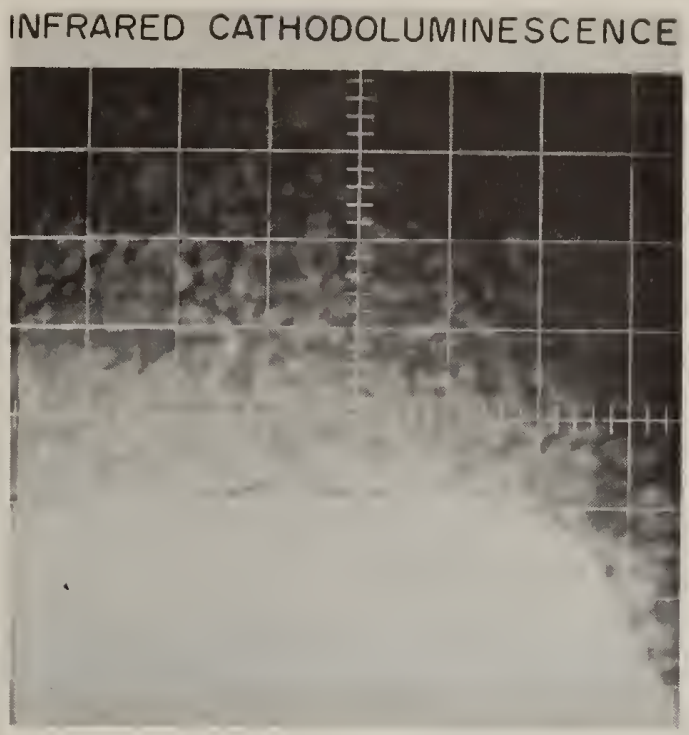

Figure 16. Infrared cathodoluminescence scanning. image. The specimen is a tellurium-doped n-type galiium arsenide, diffused with zinc from the vapor phase to form a $p-n$ junction. The dark region is p-type. Area scanned: $350 \mu \times 250 \mu$. Courtesy of D. B. Wittry.

9. MULTIPLE SCAN EXPOSURES

Line and area scans of different types can be superposed for better presentation [37]. A line scan can frequently be understood better if accompanied by a target current area scan marking the beam trajectory of the line scan (figure 11). Similarly, the combination of a concentration map with a target current area scan is frequently useful.

The use of multiple exposures in different colors [38] offers further possibilities to combine several signals in a single representation. 


\section{REFERENCES}

[1] Castaing, R. and Guinier, A., "Application of Electron Beams to Metallograph1cal Analysis" (French), Proceedings, Conference on Electron Microscopy, Delft (1949), p. 60, Martinus, Nijhoff, The Hague, 1950.

[2] Moseley, H. G. J., "The High-frequency Spectra of the Elements," Phil. Mag., Vol. 26, p. 1024 (1913), Vol. 27, p. 703 (1913).

[3] Castaing, R. and Descamps, J., "On the Physical Fundaments of Point Analysis by X-Ray Spectrography" (French), J. Phys. Radium, Vol. 16, p. 304 (1955).

[4] Castaing, R., "Electron Probe Microanalysis," Advances in Electronics and Electron Physics, Vol. 13, p. 317 (1960), Academic Press.

[5] Wittry, D. B., "Methods of Quantitative Electron Probe Analysis," Proceedings, Am. Soc. Testing Mats. Symposium, Atlantic City, N. J., 1962. ASTM Special Technical Publication No. 349, p. 128.

[6] Cosslett, V. E., Introduction to Electron Optics, The Clarendon Press, Oxford, 1950 (2nd Ed.).

[7] Johannson, T., "On a Novel Exactly Focusing X-Ray Spectrometer" (German), Z. Phys., Vol. 82, p. 507 (1933).

[8] Johann, H. H., "Production of Intense X-Ray Spectra by Means of Concave Crystals" (German), Z. Phys., Vol. 69, p. 185 (1931).

[9] Ogilvie, R. E., "X-Ray Optics in Electron Microanalysis," Proceedings, Am. Soc. Testing Mats. Symposium, At lantic City, N. J., 1962. ASTM Special Technical Publication No. 349, p. 17 .

[10] Borovski1, I. B., "X-Ray Spectrographic Chemical Microanalysis of an Isolated Spot of a Surface" (Russian), Akademiya Nauk SSSR., Sbornik, Problemy Metallurgi1, Akad. I. P. Bardinu, K 70-Letiyu (1953), p. 135 .

[11] von Ardenne, M., "The Scanning Electron Microscope. Practical Construction" (German), Z. Techn. Physik, Vol. 19, p. 407 (1938). 
[12] Smith, K. C. A. et al., "The Scanning Electron Microscope and Its Fields of Application," Brit. J. Appl. Phys., Vol. 6, p. 391 (1955).

[13] Everhart, T. E., "Certain Semiconductor Applications of the Scanning Electron Microscope," The Electron Microprobe, Proceedings, Symposium of the Electrochemlcal Society, J. Wiley \& Sons, New York, 1966, p. 665 .

[14] Cosslett, V. E. and Duncumb, P., "Microanalysis by a Flying Spot X-Ray Method," Nature, Vol. 177, p. 1172 (1956).

[15] Anderson, C. A., "Electron Probe Microanalysis of Thin Layers and Small Particles with Emphasis on Light Element Determinations," The Electron Microprobe, Proceedings, Symposium of the Electrochemical Soclety, J. Wiley \& Sons, New York, 1966, p. 58.

[16] Wittry, D. B., "Resolution of Electron Probe Microanalysis," J. Appl. Phys., Vol. 29, p. 1543 (1958).

[17] Theisen. R. and Lemaître, J., "High Precision Microprobe Analysis by Thin Metallic Film Calibration, "Proceedings, $\mathrm{Xth}$ Colloquium Spectroscopicum Internationale, Spartan Books, Washington, D. C., 1963, p. 391.

[18] Heinrich, K. F. J., "Interrelationships of Sample Composition, Backscatter Coefficient, and Target Current Measurement," Advances in X-Ray Analysis, Vol. 7, p. 325 (1964).

[19] Everhart, T.E., Wells, O. C., and Oatley, C. W., "Factors Affecting Contrast and Resolution in the Scanning Electron Microscope," J. Electronics and Control, Vol. 7, p. 97 (1959).

[20] Burhop, E. H. S., The Auger Effect and other Radiationless Transitions, Cambridge University Press, Cambridge, England, 1952.

[21] Palluel, P., "The Backscattered Component of Secondary Electron Emission of Metals" (French), Compt. Rend., Vol. 224, p. 1492 (1947).

[22] Rouberol, M. et al., "Automatic Scanning Device for the Microsonde CAMECA, Principle and Examples of Application" (French), Mem. Sc1.Rev. Met., Vo1. 59, p. 305 (1962). 
[23] Nealey, C. C., Laakso, C. W., and Hagen, P. J., "Planar Silicon Device Analyses with the Electron Probe Microanalyzer," The Electron Microprobe, Proceedings, Symposium of the Electrochemical Society, J.Wiley \& Sons, New York, 1966, p. 748.

[24] Lander, J. J., Schreiber, H., Jr., Buck, T. Mo, and Mathews, J.R., "Microscopy of Internal Crystal Imperfections in Si $\mathrm{p}-\mathrm{n}$ Junction Diodes by Use of Electron Beams," Appl. Phys. Letters, Vol. 3, p. 206 (1963).

[25] Dorsey, J. R., "Scanning Electron Probe Measurement of Magnetic Fields," First National Symposium on Electron Probe Microanalysis, U. of Maryland, 1966. Advances in Electronics and Electron Physics, Academic Press (to be published)。

[26] Melford, D. A., "The Use of Electron-Probe Microanalysis in Physical Metallurgy," J. Inst. Metals, Vol. 90, p. 217 (1962).

[27] Heinrich, K. F。 J., "Concentration Mapping Device for the Scanning Electron Probe Microanalyzer," Rev. Sci. Instr., Vol. 33, p.884 (1962).

[28] Scribner, B. F. (editor), "Activities of the NBS

Spectrochemical Analysis Section, July 1965 to June 1966." NBS Technical Note 401 (in press).

[29] Heinrich, K. F. J., "Oscilloscope Readout of Electron Microprobe Data," Advances in X-Ray Analysis, Vol. 6, p. 291 ( 1962 ).

[30] Moore, G. A., "Direct Quantitative Analysis of Photomicrographs by a Digital Computer, "Photogr. Science and Engr., Vol. 8, p. 152 (1964).

[31] Dorfler, G. and Plockinger, E., "A New Device for Determining Relative Areas of Metallic and Non-metallic Phases with the Electron Probe" (German), Archiv Elsenhdttenwesen, Vol. 36, p. 649 (1965).

[32] Liebhafsky, $H_{0} A_{\circ}$, Pfeiffer, H. G., and Zemany, P. D., "Precision in X-Ray Emission Spectrography," Analytical Chemistry, Vol. 27, p. 1257 (1955). 
[33] Long, J. V. P., "The Application of the Electron-Probe Microanalyzer to Metallurgy and Mineralogy," X-Ray Optics and X-Ray Microanalysis, Proceedings, Third Internat. Symposium, Stanford, Academic Press, New York and London, 1963, p. 288.

[34] Heinrich, K. F. J., "Electron Probe Analysis in Metallurgical Research," Proceedings, Am. Soc. Testing Mats. Symposium, Atlantic Clty, N.J., 1962. ASTM Special Technical Publication No. 349, p. 178.

[35] Wittry, D. B. and Kyser, D. F., "Cathodoluminescence at $\mathrm{p}-\mathrm{n}$ Junctions in GaAs," J. Appl. Phys. Vol. 36, p. 1387 $(1965)$.

[36] Kyser, D. K. and Wittry, D. B., "Cathodoluminescence in Galilum Arsenide," The Electron Microprobe, Proceedings, Symposium of the Electrochemical Society, J. Wiley \& Sons, New York, 1966, p. 691.

[37] Wittry, D. B. and Fitzgerald, R., "Equipment for Beam Scanning and Step Scanning in Electron-Probe Analysis," Advances in X-Ray Analysis, Vol. 5, p. 549 (1962).

[38] Heinrich, K. F. J., "Instrumental Developments for Electron Microprobe Readout," Advances in X-Ray Analysis, Vol. 7, p. 393 (1964). 


OFFICIAL BUSINESS 